\title{
A new model for the global biogeochemical cycle of carbonyl sulfide - Part 1: Assessment of direct marine emissions with an oceanic general circulation and biogeochemistry model
}

\author{
T. Launois ${ }^{1}$, S. Belviso ${ }^{1}$, L. Bopp ${ }^{1}$, C. G. Fichot ${ }^{2}$, and P. Peylin ${ }^{1}$ \\ ${ }^{1}$ Laboratoire des Sciences du Climat et de l'Environnement (LSCE Saclay), IPSL, CEA, CNRS, UVSQ, CE Saclay, \\ Bât 703 L’Orme des Merisiers, 91191, Gif-sur-Yvette, France \\ ${ }^{2}$ Jet Propulsion Laboratory, California Institute of Technology, Pasadena, California, USA
}

Correspondence to: T. Launois (thomas.launois@1sce.ipsl.fr)

Received: 22 May 2014 - Published in Atmos. Chem. Phys. Discuss.: 11 August 2014

Revised: 30 November 2014 - Accepted: 6 February 2015 - Published: 3 March 2015

\begin{abstract}
The global budget of tropospheric carbonyl sulfide (OCS) is believed to be at equilibrium because background air concentrations have remained roughly stable over at least the last decade. Since the uptake of OCS by leaves (associated with photosynthesis) and soils have been revised significantly upwards recently, an equilibrated budget can only be obtained with a compensatory source of OCS. It has been assumed that the missing source of OCS comes from the low-latitude ocean, following the incident solar flux. The present work uses parameterizations of major production and removal processes of organic compounds in the NEMOPISCES (Nucleus for European Modelling of the Ocean, Pelagic Interaction Scheme for Carbon and Ecosystem Studies) ocean general circulation and biogeochemistry model to assess the marine source of OCS. In addition, the OCS photo-production rates computed with the NEMO-PISCES model were evaluated independently using the UV absorption coefficient of chromophoric dissolved organic matter (derived from satellite ocean color data) and apparent quantum yields available in the literature. Our simulations show global direct marine emissions of OCS in the range of 573$3997 \mathrm{GgS} \mathrm{yr}^{-1}$, depending mostly on the quantification of the absorption rate of chromophoric dissolved organic matter. The high estimates of that range are unlikely, as they correspond to a formulation that most likely overestimate photoproduction process. Low and medium $\left(813 \mathrm{GgS} \mathrm{yr}^{-1}\right)$ estimates derived from the NEMO-PISCES model are however consistent spatially and temporally with the suggested missing source of Berry et al. (2013), allowing us thus to close
\end{abstract}

the global budget of OCS given the recent estimates of leaf and soil OCS uptake.

\section{Introduction}

Carbonyl sulfide (OCS) is a long-lived sulfur-containing trace gas with direct and indirect effects on the radiation budget of the atmosphere (OCS being both a tropospheric greenhouse gas and a source of stratospheric sulfur aerosols). But these radiative effects are low compared to the radiative forcings of greenhouse gases (GHG) and tropospheric aerosols of anthropogenic origin (Brühl et al., 2012, and references therein). However, because OCS is the most abundant sulfurcontaining gas in the atmosphere, it is a major contributor to the stratospheric sulfate layer during volcanically quiescent periods (Notholt et al., 2003). OCS also participates in some key reactions within the global carbon cycle, especially reactions associated with leaf photosynthesis and soil microbial activities (Berry et al., 2013, and references therein). As such, it holds great promises for the studies of plant physiology, terrestrial ecosystem production and the global carbon cycle thanks to its potential use as a tracer for canopy photosynthesis, transpiration and stomatal conductance (Wohlfahrt et al., 2012, and references therein).

Measurements of OCS from the global air-monitoring network of the National Oceanic and Atmospheric Administration (NOAA) provided compelling evidence for the existence of a major sink of this gas in the continental bound- 
ary layer, mainly attributed to biospheric uptake (Montzka et al., 2007; Campbell et al., 2008). The uptake of OCS by plants was modeled to be no more than $240 \mathrm{GgS} \mathrm{yr}^{-1}$ by Kettle et al. (2002), but it has been recently revised upwards, with new estimates of $490 \mathrm{GgS} \mathrm{yr}^{-1}$ (Suntharalingam et al., 2008), of $738 \mathrm{GgS} \mathrm{yr}^{-1}$ in the work of Berry et al. (2013) and even reaching up to $1500 \mathrm{GgS} \mathrm{yr}^{-1}$ in Montzka et al. (2007). Soils could also play a role in the budget of OCS. It is still a strong matter of debate, but recent estimates suggest that much more OCS is taken up by soils than proposed by Kettle et al. (2002) (355 $\mathrm{GgS} \mathrm{yr}^{-1}$, according to Berry et al., 2013, compared with an estimate of around $130 \mathrm{GgS} \mathrm{yr}^{-1}$ in Kettle et al., 2002). Since background air concentrations have remained roughly stable over at least the last decade (Montzka et al., 2007), the global budget of tropospheric OCS is believed to be at equilibrium. Kettle et al. (2002) proposed a global budget of OCS with ocean and anthropogenic sources compensating for the main uptake by vegetation. However, because deposition fluxes of OCS to vegetation and soils are 3 times higher than proposed in the study by Kettle et al. (2002), an equilibrated budget can only be obtained with a compensatory source of OCS. Berry et al. (2013) suggests that the missing source of OCS comes from the oceans. This missing source has been inferred through a simple inversion approach that optimizes sources and sinks based on global measurements of atmospheric OCS mixing ratios collected in the NOAA network. This inversion points towards a larger global oceanic source of OCS with higher proportions of tropical emissions than previously established.

The ocean is believed to be the largest source of atmospheric OCS (Chin and Davis, 1993; Kettle et al., 2002; Berry et al., 2013). It contributes to OCS in the troposphere by direct emission of this gas, and by large emissions of carbon disulfide $\left(\mathrm{CS}_{2}\right)$ and dimethylsulfide (DMS), quickly oxidized into OCS (with an approximate lifetime of 1 day) (Barnes et al., 1997; Kloster, 2006). Barnes et al. (1997) suggested that OCS accounts for $0.7 \%$ of the oxidation products of DMS, and that $87 \%$ of the marine emissions of $\mathrm{CS}_{2}$ are converted into OCS. However, estimates of sea-air fluxes of OCS and their spatial distributions remain largely unknown. Kettle et al. (2002) simulated direct global oceanic OCS fluxes from $-110 \mathrm{GgS} \mathrm{yr}^{-1}$ (a sink) to $190 \mathrm{GgS} \mathrm{yr}^{-1}$ (a source to the atmosphere), while previous estimates based on field observations suggested global direct oceanic OCS emissions from between 160 and $640 \mathrm{GgS} \mathrm{yr}^{-1}$ (Chin and Davis, 1993; Watts, 2000). The Kettle et al. (2002) study suggested that direct sea-air OCS emissions mainly take place at midand high latitudes, during the respective periods of maximum irradiance.

OCS surface concentrations show a strong diurnal cycle with a mid-afternoon maximum, suggesting that photoproduction is a major source of marine OCS (Ferek and Andreae, 1984; Xu et al., 2001; Von Hobe et al., 2003). In addition, OCS can also be produced in marine waters when no light is available. This pathway is therefore called dark production. Measurements by Von Hobe et al. (2001) indicated that its rate is proportional to the amount of organic material, and it has therefore so far been linked to the chromophoric dissolved organic matter (CDOM) absorption coefficient (Von Hobe et al., 2001, 2003). Finally, OCS surface concentrations and fluxes are also strongly influenced by the continuous temperature- and $\mathrm{pH}$-dependent hydrolysis of OCS to carbon dioxide $\left(\mathrm{CO}_{2}\right)$ and hydrogen sulfide $\left(\mathrm{H}_{2} \mathrm{~S}\right)$ (Von Hobe et al., 2003).

The present work reassesses the marine source of OCS using the 3-D oceanic NEMO-PISCES (Nucleus for European Modelling of the Ocean, Pelagic Interaction Scheme for Carbon and Ecosystem Studies) ocean general circulation and biogeochemistry model with process-based parameterizations of the main OCS production and removal processes (Fig. 1). The present study proposes two independent approaches to quantify the photo-production of OCS. The dark production rate implemented in the NEMO-PISCES model follows the formulation of Von Hobe et al. (2001, 2003). Therefore, the dark production rate, even if assumed to be light-independent, is also linked to the chromophoric dissolved organic matter absorption coefficient at $350 \mathrm{~nm}\left(a_{350}\right)$, as the variable provides an indirect estimate of the seawater richness in organic matter. As parameterizations found in literature for both dark and photo-production of OCS are related to the UV absorption coefficient of CDOM at $350 \mathrm{~nm}$, sensitivity tests are performed using three different formulations for this variable. Sensitivity tests are also performed on hydrolysis, exploring two different formulations. Global maps of OCS concentrations obtained with the NEMO-PISCES model are compared with in situ measurements. Finally, the magnitude and spatial distributions of global OCS emissions modeled in the present work are compared to previous global estimates.

\section{Methods}

\subsection{Description of NEMO-PISCES and experimental design}

In this study, we use the Pelagic Interaction Scheme for Carbon and Ecosystem Studies (PISCES) ocean biogeochemical model. As a detailed description of the model parameterizations is given in Aumont and Bopp (2006), the model is only briefly presented here. The model has 24 compartments, including four living pools: two phytoplankton size classes/groups (nanophytoplankton and diatoms) and two zooplankton size classes (microzooplankton and mesozooplankton). Phytoplankton growth can be limited by five different nutrients: nitrate, ammonium, phosphate, silicate and iron. The internal concentrations of chlorophyll for both phytoplankton groups are prognostically simulated with chlorophyll-to-carbon ratios computed as a function of light and nutrient stress. There are three nonliving compartments: 


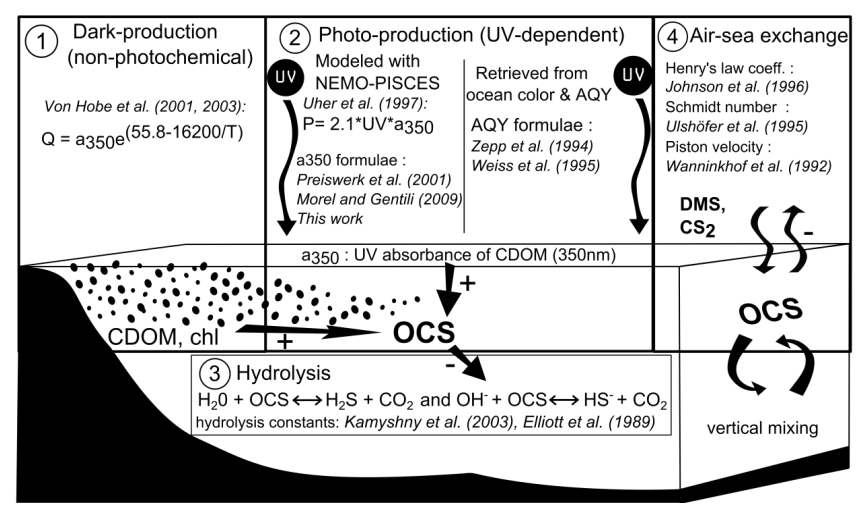

Figure 1. Main production and removal processes implemented in the NEMO-PISCES ocean general circulation and biogeochemistry model to simulate the marine OCS cycle: dark production, photoproduction and hydrolysis. Of central importance is the UV absorption coefficient at $350 \mathrm{~nm}$ of chromophoric dissolved organic matter (CDOM) which is derived from modeled $\mathrm{Chl}$ concentrations using three different relationships linking $a_{350}$ to Chl. The simulated photo-production rates of OCS were evaluated independently using the model of Fichot and Miller (2010) and published apparent quantum yields (AQY). Aqueous OCS is removed by hydrolysis (two different formulations of the hydrolysis rate are used), lost or absorbed at the air-sea interface and mixed both vertically and horizontally. Studies relevant for sensitivity tests and model parameterization presented in this paper are displayed in italic. Oceans also emit DMS and $\mathrm{CS}_{2}$ which are later oxidized in OCS in the atmosphere. These indirect sources of OCS are not detailed in the present study.

semi-labile dissolved organic matter (with remineralization timescales of several weeks to several years), small and large sinking particles. In addition to the version of the model used in Aumont and Bopp (2006), we also include here a prognostic module computing OCS concentrations in seawater.

PISCES is coupled to the general circulation model NEMO (Madec et al., 2008). A release of the model is available for the community at http://www.nemo-ocean.eu/. Here, we use the global configuration ORCA2 with a resolution of $2^{\circ} \times 0.5-2^{\circ}$ and 31 vertical levels (with a $\sim 10 \mathrm{~m}$ resolution in the first $200 \mathrm{~m}$ ). NEMO-PISCES is first run 3000 years to obtain an equilibrated state, forced in offline mode by the Consortium for Oceanic Research and Education (CORE2) Normal Year Forcing, (Large and Yeager, 2008) and initialized with climatological nutrient data. The OCS module is then only run 2 additional years as it converges towards equilibrium much more rapidly. The results presented in this study correspond to the last year of this simulation.

\subsection{Parameterizations of OCS production and removal processes implemented in NEMO-PISCES}

The clear diurnal cycle of sea-surface OCS concentrations with peak values during mid-afternoon suggests photochemical processes play an important role in the production of
OCS. Organo-sulfur compounds with thiol groups (-SH), such as cysteine and methyl mercaptans $\left(\mathrm{CH}_{3} \mathrm{SH}\right)$, have been suggested as OCS precursors (Ferek and Andreae, 1984; Flöck et al., 1997; Ulshöfer et al., 1996). Moreover, measured $\mathrm{CH}_{3} \mathrm{SH}$ diurnal cycles were coherent with the hypothesis that its photo-destruction could lead to OCS production (Xu et al., 2001). Because no global map of $\mathrm{CH}_{3} \mathrm{SH}$ is available, we followed parameterizations of OCS photoproduction found in literature which relate photo-production rate of OCS to the UV irradiance intensity at the sea surface and to the efficiency of chromophoric dissolved organic matter (CDOM) available to absorb this UV radiation. The quantification of this photochemical process is amenable to remote sensing because of its critical dependence on ocean UV and visible optical properties. Additional parameterizations were needed to complete the description of OCS formation and destruction processes in NEMO-PISCES. We therefore implemented specific equations to calculate the formation of OCS via dark production (a light-independent pathway) and the hydrolysis rate of OCS in seawater. Finally, air-sea exchanges of OCS were described in an analogous way to Fick's diffusion law.

\subsubsection{UV light penetration in seawater}

In NEMO-PISCES, surface irradiance received at each grid point is a function of cloud coverage and deduced surface UV irradiance is taken equal to $4.4 \%$ of the total light received at sea surface. UV penetration at depth in marine waters in NEMO-PISCES was taken equal to the penetration calculated with the deep blue wavelength for visible light attenuation coefficient. As this is a rough approximation and might lead to overestimating maximum depth penetration for UV irradiance, we set the UV value to zero for layers deeper than $30 \mathrm{~m}$, which corresponds to the average depth at which less than $10 \%$ of surface UV irradiance penetrates for marine waters containing less than $1 \mathrm{mg} \mathrm{m}^{-3}$ of chlorophyll (Bricaud et al., 1995; Tedetti and Sempéré, 2006).

\subsubsection{Parameterization of CDOM absorption coefficient at $350 \mathrm{~nm}\left(a_{350}\right)$}

Chromophoric (or colored) dissolved organic matter $(\mathrm{CDOM})$ is the fraction of the dissolved organic matter that absorbs light, ranging from ultraviolet to visible wavelengths. CDOM has been identified as one of the most influential factors controlling UV attenuation in waters. Its concentration increases in seawater with elevated biological production rates and terrestrial inputs. CDOM distribution is also controlled by the deep ocean circulation, upwelling and/or vertical mixing (Para et al., 2010, and references therein). Its concentration decreases with photochemical degradation and microbial consumption. CDOM absorbs part of available light, therefore negatively impacting primary productivity of aquatic ecosystems. However, as provider 
of a substitute for microbial respiration, photo-degraded CDOM positively impacts the secondary productivity of the oceanic ecosystems.

As no reliable parameterization is currently available to calculate CDOM concentrations, due to insufficient knowledge on the controlling processes of CDOM formation and destruction, we chose to follow the study of Para et al. (2010) and assumed that the CDOM absorption at $350 \mathrm{~nm}\left(a_{350}\right)$ was a good indicator of CDOM concentrations. The wavelength of $350 \mathrm{~nm}$ was chosen because it corresponds to the maximum sensitivity of the Eppley UV light sensors used during the marine campaigns where links between CDOM concentration, CDOM absorption and OCS production were established (Uher and Andreae, 1997; Preiswerk and Najjar, 2000). This wavelength has also been proven to be the most efficient for the photochemical excitation of dissolved organic matter (Farmer et al., 1993). OCS production is either dependent on irradiance in the UV domain (photoproduction) or on CDOM and organic matter concentration (dark production). As $a_{350}$ allows for a link with both variables, it is a key parameter in our parameterizations of OCS production. Sensitivity tests were performed using NEMOPISCES and three different formulations of $a_{350}$.

The first two formulations of CDOM absorption coefficients were proposed by Morel and Gentili (2009) and Preiswerk and Najjar (2000), who deduced them at a given wavelength from in situ measurements, and then extrapolated the absorption coefficient of CDOM at $350 \mathrm{~nm}$ by using the following standard exponential relationship:

$a_{\mathrm{CDOM}}(\lambda)=a_{\mathrm{CDOM}}($ ref $) \times \mathrm{e}^{(-S \times(\text { ref }-\lambda))}$,

where $S$ is the spectral slope coefficient of CDOM between $\lambda$ and the reference wavelength (ref).

\section{$a_{350}$ from Morel and Gentili (2009)}

The parameterization of $a_{350}$ from Morel and Gentili (2009) is based on spectral reflectances of the ocean over case 1 waters. Case 1 waters are those for which the optical properties of CDOM closely follow the optical properties of phytoplankton, as defined in Morel (1988). Spectral reflectances were derived from ocean color remote sensing data at several wavelengths to allow separation between CDOM and chlorophyll reflectance signatures. Products from SeaWiFS monthly global composites for the 2002-2007 period were used, and led to the following relationship between CDOM absorption coefficient and chlorophyll concentration:

$a_{\mathrm{CDOM}}(400)=0.065[\mathrm{Chl}]^{0.63}$.

\section{$a_{350}$ from Preiswerk and Najjar (2000)}

The second parameterization was taken from Preiswerk and Najjar (2000) who deduced $a_{350}$ from modeled CDOM absorption coefficient at $440 \mathrm{~nm}$. To model $a_{440}$, satellite ocean color data were used as a proxy for chlorophyll concentration and combined with the relationship of Garver and Siegel (1998), Eq. (2):

$\operatorname{per}\left(a_{440}\right)=-26[\log (\mathrm{chl})]+26$

$a_{\mathrm{PH}, 440}=0.0448 \mathrm{chl}$,

$\operatorname{per}\left(a_{440}\right)=\frac{a_{440}}{a_{\mathrm{PH}, 440}+a_{440}} \times 100 \%$,

where $a_{\mathrm{PH}, 440}$ is the absorption coefficient of the phytoplankton at $440 \mathrm{~nm}$, and per $\left(a_{440}\right)$ is the percent of the total nonseawater absorption coefficient at $440 \mathrm{~nm}$ (due to CDOM).

\section{$a_{350}$ from MODIS Aqua ocean color data}

A relationship between $a_{350}$ and Chlorophyll $a$ was established independently, using MODIS Aqua ocean color data collected continuously between July 2002 and July 2010 . Monthly climatologies of MODIS Aqua Chlorophyll $a$ surface concentrations were used, and MODIS Aqua remotesensing reflectances were used to derive corresponding monthly climatologies of $a_{350}$ for the global surface ocean. The SeaUV algorithm developed by Fichot et al. (2008) was used to estimate the diffuse attenuation coefficient at $320 \mathrm{~nm}, K_{\mathrm{d}}(320)$, from the remote-sensing reflectances. A ratio $a_{\mathrm{CDOM}}(320) / K_{\mathrm{d}}(320)=0.68$ derived from an extensive set of in situ measurements was then used to calculate the absorption coefficient of CDOM at $320 \mathrm{~nm}, a_{320}$, from $K_{\mathrm{d}}(320)$ (Fichot and Miller, 2010). A spectral slope coefficient of 0.0198 derived from the same in situ data set was then used to calculate $a_{350}$ from $a_{320}$ using Eq. (1).

The $a_{350}$ data from the twelve monthly climatologies were regressed on the corresponding MODIS Aqua Chlorophyll $a$ concentrations using the fourth-order polynomial shown in Eq. (6).

$$
\begin{aligned}
\ln \left(a_{350}\right) & =0.5346 C-0.0263 C^{2}-0.0036 C^{3} \\
& +0.0012 C^{4}-1.6340,
\end{aligned}
$$

where $C$ is the chlorophyll concentration in $\mathrm{mg} \mathrm{m}^{-3}$, and $a_{350}$ has units of $\mathrm{m}^{-1}$.

The Eq. (6) was then added in NEMO-PISCES to complete the sensitivity tests of the OCS concentrations on the different $a_{350}$ expressions tested.

\subsubsection{OCS photo-production rates as modeled in NEMO-PISCES}

OCS photo-production is primarily induced by the interaction of UV radiation and natural photosensitizers in CDOM (Ferek and Andreae, 1984; Flöck et al., 1997). Therefore, the 
Uher and Andreae (1997) photo-production parameterization takes into account both the incident UV irradiance and OCS production efficiency (apparent quantum yield, AQY). An AQY represents the spectral efficiency of a photochemical process (e.g., photochemical production of OCS), and is generally determined in the laboratory by normalizing the quantity of OCS produced during solar exposure to the amount of photons absorbed by CDOM during that same solar exposure. The resulting expression for photoproduction rate proposed is

$P=p \mathrm{UV}$,

where $P$ is the OCS photo-production rate, $p$ a zeroth-order photoproduction constant $\left(\mathrm{fmol} \mathrm{L}^{-1} \mathrm{~s}^{-1} \mathrm{~W}^{-1} \mathrm{~m}^{-2}\right)$ and UV the solar UV light density.

This expression was established using strong assumptions, such as considering that no other source or sink of OCS affects OCS concentration in seawaters. In their study, Uher and Andreae (1997) measured mean values for the photoproduction constant $p$ around $1.3 \pm 0.3 \mathrm{fmol} \mathrm{L}^{-1} \mathrm{~s}^{-1} \mathrm{~W}^{-1} \mathrm{~m}^{-2}$ on offshore samples and values twice as high in inshore waters, around $2.8 \pm 0.3 \mathrm{fmol} \mathrm{L}^{-1} \mathrm{~s}^{-1} \mathrm{~W}^{-1} \mathrm{~m}^{-2}$ (all measurements done in April 1993, in the North Sea).

A few AQY for OCS have been published, but they exhibit considerable variability, with values varying by a factor of $>7$ depending on the environment considered (quantum yields ranging from $9.3 \times 10^{-8}$ to $6.4 \times 10^{-7}$ in the Sargasso Sea for Weiss et al., 1995a, and Zepp and Andreae, 1994, respectively). The quantum yields depend both on the location and the season of the measurement, especially considering that CDOM quality and its absorption coefficient might vary through time (Kettle et al., 2002; Weiss, 1995b; Cutter et al., 2004). To compensate for part of this natural variability, Uher and Andreae (1997) normalized the measured AQY by the absorption coefficient of CDOM available for the reaction at the same location. Therefore, the new relationship, implemented in NEMO-PISCES, is the following:

$$
P=a_{350} \mathrm{UV} \frac{p}{a_{350}}=k a_{350} \mathrm{UV}
$$

where $P$ is the OCS photo-production rate $\left(\mathrm{pmol} \mathrm{m}^{-3} \mathrm{~s}^{-1}\right)$, and UV is the incident irradiance integrated from 295 to $385 \mathrm{~nm}\left(\mathrm{~W} \mathrm{~m}^{-2}\right)$. The $k$ coefficient is retrieved from the normalization of measured photoproduction constants to measured CDOM absorption coefficient values at $350 \mathrm{~nm}$. For offshore waters (the majority of global waters), $k$ was found in the Uher and Andreae (1997) study to be close to a value of $2.1 \mathrm{fmol} \mathrm{L}^{-1} \mathrm{~s}^{-1} \mathrm{~W}^{-1} \mathrm{~m}^{3}$. Note that the $k$ coefficient deduced from inshore water samples was found to be $2.8 \mathrm{fmol} \mathrm{L}^{-1} \mathrm{~s}^{-1} \mathrm{~W}^{-1} \mathrm{~m}^{3}$ on average. The smaller difference between the two $k$ values justified the choice of using this normalized expression rather than Eq. (7a) which showed more sample dependence.

\subsubsection{Parameterization of OCS dark production rates}

Measurements of large OCS concentrations well below the photic zones have proven that OCS can be produced when no light is available. The so-called dark production pathway was shown to largely depend on available organic matter. The pool of organic matter is quantified by the $a_{350}$ parameter, following Para et al. (2010), as explained in Sect. 2.2.2. Microbial activities are suggested as main precursors for the OCS dark production pathway, but their exact nature and the mechanisms underlying this process are poorly known. Von Hobe et al. $(2001,2003)$ calculated dark production rates assuming that after-dawn OCS concentrations were reaching a steady-state when dark production was compensating for the parallel hydrolysis. Equation (8) was established using measurements from a campaign in the Sargasso Sea and hydrolysis rates were calculated following the Elliott et al. (1989) formulation.

The formulation from Von Hobe et al. (2001) relating OCS dark production rates to the CDOM absorption coefficient was implemented in NEMO-PISCES as follows:

$Q=a_{350} \mathrm{e}^{\left(55.8-\frac{16200}{T}\right)} \quad(T$ in $\mathrm{K})$,

where $Q$ is the dark production rate in $\mathrm{pmol} \mathrm{m}^{-3} \mathrm{~s}^{-1}$, and $a_{350}$ is the CDOM absorption coefficient which is used here to describe the $\mathrm{CDOM} /$ organic matter concentration.

\subsubsection{Hydrolysis of OCS}

OCS is chemically removed in seawater through reaction with $\mathrm{H}_{2} \mathrm{O}$ and $\mathrm{OH}^{-}$:

$\mathrm{H}_{2} \mathrm{O}+\mathrm{OCS} \leftrightarrow \mathrm{H}_{2} \mathrm{~S}+\mathrm{CO}_{2}$,

$\mathrm{OH}^{-}+\mathrm{OCS} \leftrightarrow \mathrm{HS}^{-}+\mathrm{CO}_{2}$.

OCS hydrolysis rate measurements were done in the dark, using filtered water, therefore canceling the potential impact of parallel dark production. Reactions (R1a) and (R1b) are actually composites of complex mechanisms involving several intermediates, and concentrations that have been used to calculate hydrolysis rates are much larger than observed in seawater, which may lead to some errors.

We performed sensitivity tests in NEMO-PISCES by using two different hydrolysis parameterizations to study the impact of the choice of the hydrolysis constant formulation. Both Kamyshny et al. (2003) and Elliott et al. (1989) relate the value of OCS hydrolysis constant to the marine water $\mathrm{pH}$ 


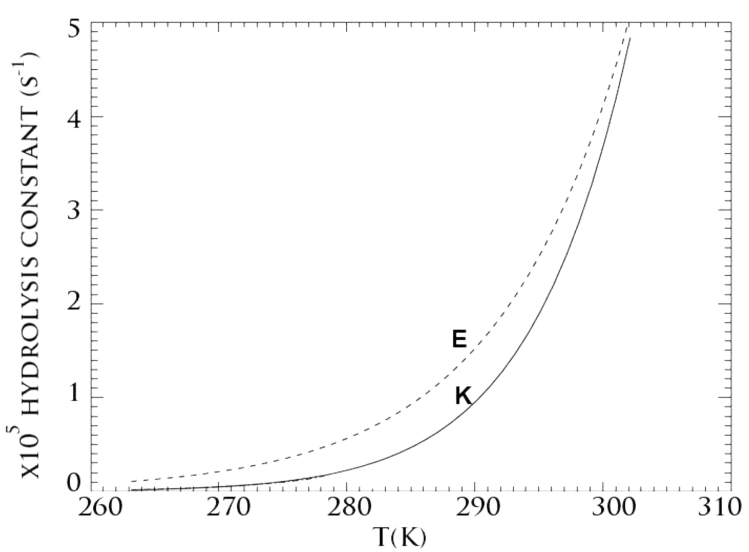

Figure 2. Temperature dependence of hydrolysis rates implemented in NEMO-PISCES. The relationships are represented for $\mathrm{pH}=8.2$, and taken from Elliott et al. (1989) (E, dashed line) and Kamyshny et al. (2003) (K, solid line).

and its temperature, respectively, as follows:

$k_{\text {hydr_Elliott }}=e^{\left(24.3-\frac{10450}{T}\right)}+\frac{k_{\mathrm{W}}}{\left[\mathrm{H}^{+}\right]} e^{\left(22.8-\frac{6040}{T}\right)}$

$(T$ in $\mathrm{K})$,

$$
\begin{aligned}
k_{\text {hydr_Kamyshny }} & =4.19 E^{-12} e^{\left(-\frac{12110}{T}\right)} \\
& +\frac{k_{\mathrm{w}}}{\left[\mathrm{OH}^{-}\right]} 1.41 E^{18} e^{\left(-\frac{-11580}{T}\right)}
\end{aligned}
$$

$(T$ in $\mathrm{K})$,

with $k_{\mathrm{w}}$ the ion product of marine water, and $\left[\mathrm{OH}^{-}\right]$and $\left[\mathrm{H}^{+}\right]$the $\mathrm{OH}^{-}$and $\mathrm{H}^{+}$activities.

Both hydrolysis constant rates, as function of temperature, are represented in the case of $\mathrm{pH}=8.2$ in Fig. 2 .

\subsubsection{OCS sea-to-air fluxes}

OCS exchange between the ocean and the atmosphere can be described in an analogous way to Fick's diffusion law. The sea-air OCS flux depends on the OCS concentration in seawater and the partial pressure of OCS in air:

$F_{\mathrm{OCS}}=k_{\mathrm{water}}\left([\mathrm{OCS}]_{\mathrm{aq}}-\frac{[\mathrm{OCS}]_{\mathrm{atm}}}{H}\right)$,

where $F_{O C S}$ is the sea-air flux $\left(\mathrm{pmol} \mathrm{m}^{-2} \mathrm{~s}^{-1}\right)$, [OCS $]_{\mathrm{aq}}$ and $[\mathrm{OCS}]_{\mathrm{atm}}$ are the OCS concentration at sea surface and in the atmosphere, respectively (in pmol m${ }^{-3}$ ). The atmospheric OCS concentration $[\mathrm{OCS}]_{\mathrm{atm}}$ over the sea surface was constantly imposed when running NEMO-PISCES, assuming an atmospheric mixing ratio of 500 ppt. Through $\mathrm{H}$, the Henry's law constant, the sea-air OCS flux also depends on the air temperature, and was implemented in NEMO-PISCES following the expression established by Johnson and Harrison (1986):

$H=e^{\left(12722-\frac{3496}{T}\right)} \quad(T$, air temperature in $\mathrm{K})$, where $k_{\text {water }}$ is the piston velocity (in $\mathrm{m} \mathrm{s}^{-1}$ ) for OCS. The coefficient is deduced from the Schmidt number of OCS, depends on surface wind speed and is calculated with the relationship of Wanninkhof (1992):

$$
\begin{aligned}
k_{\mathrm{water}} & =\left[0.3 u^{2}+2.5 \times(0.5246+0.016256 T\right. \\
& \left.\left.+0.00049946 T^{2}\right)\right] \times \sqrt{\frac{660}{S_{\mathrm{OCS}}}}
\end{aligned}
$$

( $T$, air temperature in ${ }^{\circ} \mathrm{C}$ ),

where $u$ is the wind speed (in $\mathrm{m} \mathrm{s}^{-1}$ ).

Note that Kettle et al. (2002) used similar parameterizations for the sea-surface exchange coefficient and the same relationship from Wanninkhof et al. (1992) to model the global OCS flux at sea surface to the one presented in this work.

The Schmidt number for OCS, SOCS (dimensionless), was implemented in NEMO-PISCES following the suggestion by Ulshöfer (1995) to deduce it from kinetic viscosity $(v)$ and diffusion coefficient $(D)$ (both in $\mathrm{m}^{2} \mathrm{~s}^{-1}$ ), respectively derived from

$S_{\mathrm{OCS}}=\frac{v}{D}$,

with

$$
\begin{aligned}
v & =\left(1.792747-5.126103 E^{-2} T+5.918645 E^{-4} T^{2}\right) \\
& \times 1 E^{-6} \quad\left(T, \text { air temperature in }{ }^{\circ} \mathrm{C}\right)
\end{aligned}
$$

and

$D=\left(10^{\left(\frac{-1010}{T}\right)-1.3246}\right) \times 1 E^{-4}$

( $T$, air temperature in ${ }^{\circ} \mathrm{C}$ ).

\subsection{An independent appraisal of photo-production rates}

Independently from NEMO-PISCES, the photochemical model of Fichot and Miller (2010) was used to calculate monthly climatologies of depth-integrated photo-production rates of OCS in the global ocean. Briefly, the photochemical model used three components to calculate depth-resolved photochemical rates in the global ocean: (1) a radiative transfer model for the determination of cloud-corrected UVvisible (290-490 nm) downward scalar irradiance, (2) the SeaUV algorithm (Fichot et al., 2008), used to calculate the spectral diffuse attenuation coefficient of UV and CDOM absorption coefficient (290-490 nm) from satellite ocean color data and (3) published AQY for the photochemical process of interest. To describe the observed variability in AQY, both mean values from Weiss et al. (1995a) (open ocean) and that of Zepp and Andreae (1994) (coastal ocean) were used in this study. Small modifications to the original photochemical 


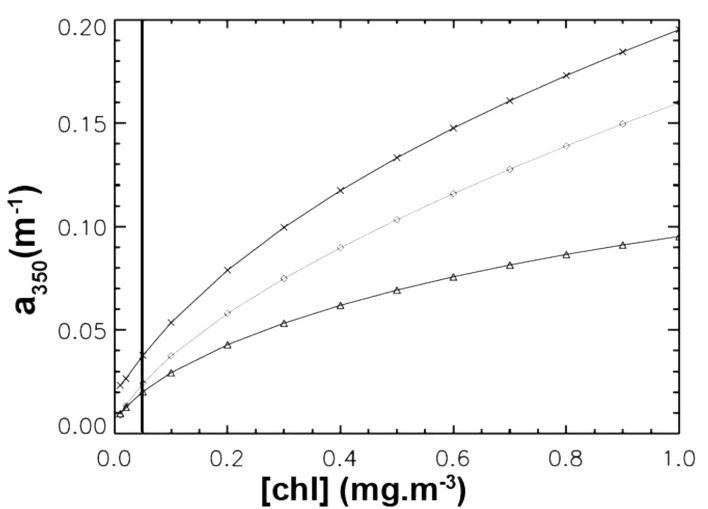

Figure 3. Relationships implemented in the NEMO-PISCES model between UV absorption coefficients for CDOM at $350 \mathrm{~nm}$ and chlorophyll concentrations. The three respective relationships are from Morel and Gentili (2009) (diamonds), Preiswerk and Najjar (2000) (triangles) or issued from this study, based on MODIS Aqua ocean color data (crosses). Chlorophyll concentrations in NEMO-PISCES have a fixed minimal value of $0.05 \mathrm{mg} \mathrm{m}^{-3}$ (thick vertical line).

model were also made, including the use of MODIS Aqua ocean color data (instead of SeaWiFS), and the use of $2 \mathrm{~nm}$ spectral resolution (instead of $5 \mathrm{~nm}$ ). The photoproduction rates are later compared to the NEMO-PISCES-simulated rates and to other seawater measurements (e.g., Cutter et al., 2004).

\section{Results}

The absorption coefficient of CDOM at $350 \mathrm{~nm}\left(a_{350}\right)$ increased monotonically with chlorophyll concentration for low chlorophyll contents. The different $a_{350}$-chlorophyll relationships used in this paper led to large differences in $a_{350}$ estimates, especially at high chlorophyll levels in seawater (Fig. 3). Estimates of $a_{350}$ obtained with the relationship based on MODIS Aqua ocean color data, which we proposed (Eq. 6), provided values 2 to 3 times larger than $a_{350}$ values obtained with the relationship from Preiswerk and Najjar (2000). Since both photo- and dark production are modeled as linear functions of $a_{350}$, underestimating/overestimating chlorophyll concentrations directly lead to underestimated/overestimated OCS production. Therefore, the evaluation of chlorophyll concentration is of capital importance in the present work.

\subsection{Evaluation of chlorophyll concentration at the global scale}

Modeled annual mean surface chlorophyll concentrations from NEMO-PISCES compared relatively well with SeaWiFS chlorophyll observations (Fig. 4). The model correctly represented main spatial patterns with, for instance, high lat- itudes showing higher annual mean chlorophyll concentrations and a stronger seasonal cycle. Observed mid- and highlatitude chlorophyll levels showed values 3 to 4 times larger than chlorophyll levels in tropical regions, which was also well captured with NEMO-PISCES. However, the model generally underestimated the chlorophyll concentration in the most oligotrophic subtropical zones of the global ocean.

\subsection{Evaluation of the depth-distribution of $a_{350}$ and OCS concentrations}

In order to provide an evaluation of modeled vertical distributions of OCS concentrations, in this subsection we present vertical monthly mean profiles of $a_{350}$ and OCS concentration from 1-D simulation runs with NEMO-PISCES. Wherever possible, we compared these simulated profiles with relevant in situ measurements. A majority of them were taken at the Bermuda Atlantic Time-series Study (BATS) site $\left(31^{\circ} \mathrm{N}\right.$, $64^{\circ} \mathrm{W}$ ). In situ measurements for OCS concentrations remain scarce at this point. Evaluations of the contribution of each individual OCS formation and destruction processes are even scarcer. Therefore, the cruise measurements around the BATS site from Cutter et al. (2004) are often used as a reference.

\subsubsection{Vertical profiles for $a_{350}$}

Our MODIS Aqua based extrapolation (Eq. 6) resulted in the highest values of simulated $a_{350}$ (up to $0.15 \mathrm{~m}^{-1}$, both in January and in August), while the parameterization from Preiswerk and Najjar (2000) resulted in $a_{350}$ values that were about half as much (Fig. 5), consistent with the difference in the respective $a_{350}$-chlorophyll formulations (Fig. 3). Values for $a_{350}$ deduced from Morel and Gentili (2009) (Eq. 2) gave an intermediary result. The pronounced August maximum around $80 \mathrm{~m}$ depth (Fig. 5b) reflected a chlorophyll content maximum at this depth $\left(a_{350}\right.$ is monotonically increasing for low levels of chlorophyll). In contrast, low $a_{350}$ values near the surface translated to a local minimum in the chlorophyll content. Note also the abrupt decrease of chlorophyll concentrations, and therefore the decreasing $a_{350}$, for depths below $80 \mathrm{~m}$ in August. In January the mixed layer was $120 \mathrm{~m}$ thick in NEMO-PISCES at the BATS site (Fig. 5a). Chlorophyll content (thus $a_{350}$ ) remained high and constant over the first $120 \mathrm{~m}$ of the ocean before an abrupt decrease in the pycnocline. For both January and August, chlorophyll concentrations and $a_{350}$ values became negligible below $200 \mathrm{~m}$, with the exception of $a_{350}$ calculated with the relationship proposed in this work.

\subsubsection{Vertical OCS concentration profiles}

Differences in $a_{350}$ estimations using the relationships in Eqs. (2)-(6) led to three-fold difference between the most extreme near-surface OCS maximum concentrations simulated by NEMO-PISCES (from 100 to $300 \mathrm{pmol} \mathrm{L}^{-1}$ in August 


\section{A) SeaWIFS annual mean}

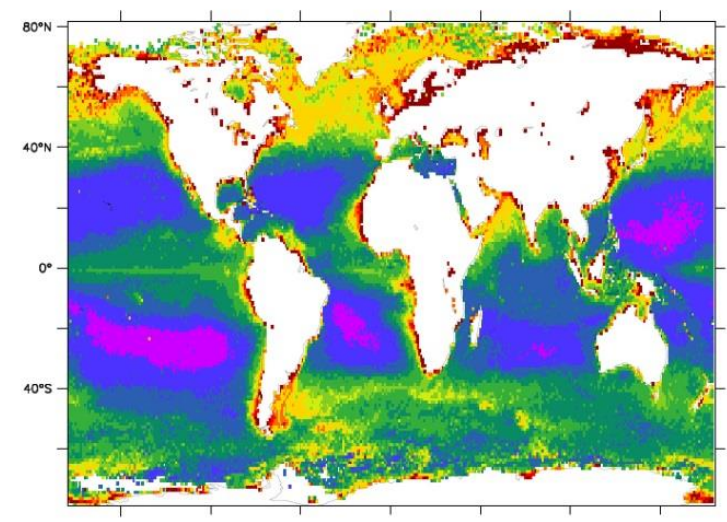

C) SeaWIFS monthly zonal mean

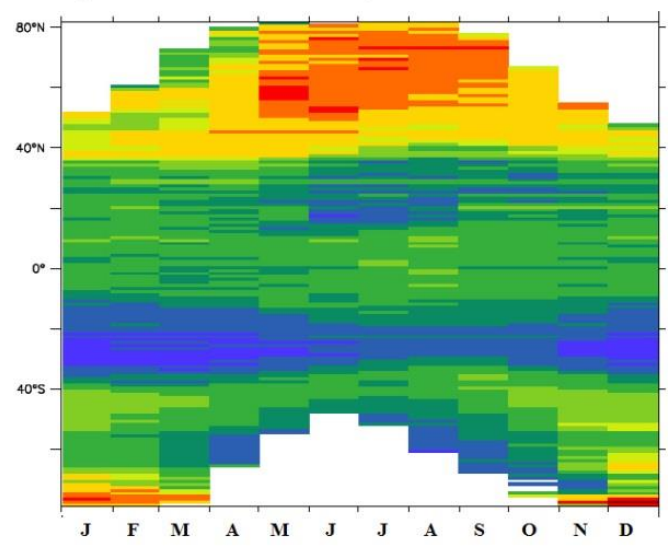

B) NEMO-PISCES annual mean

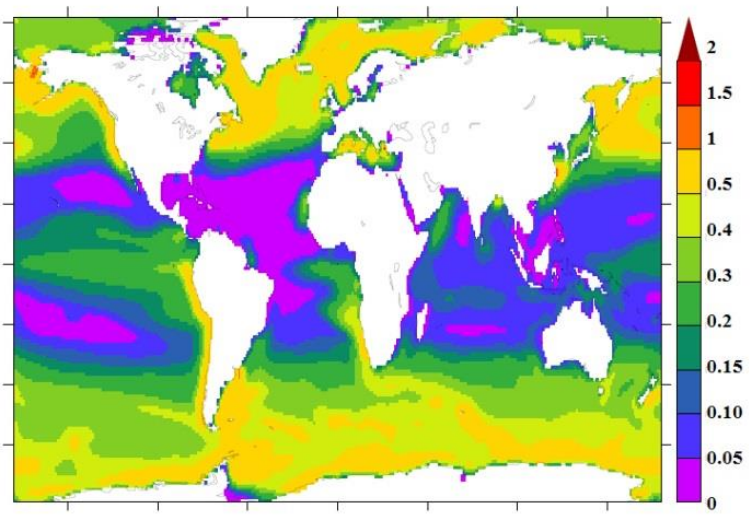

[chl] $\left(\mathrm{mg}^{\mathrm{m}} \mathrm{m}^{-3}\right)$
D) NEMO-PISCES monthly zonal mean

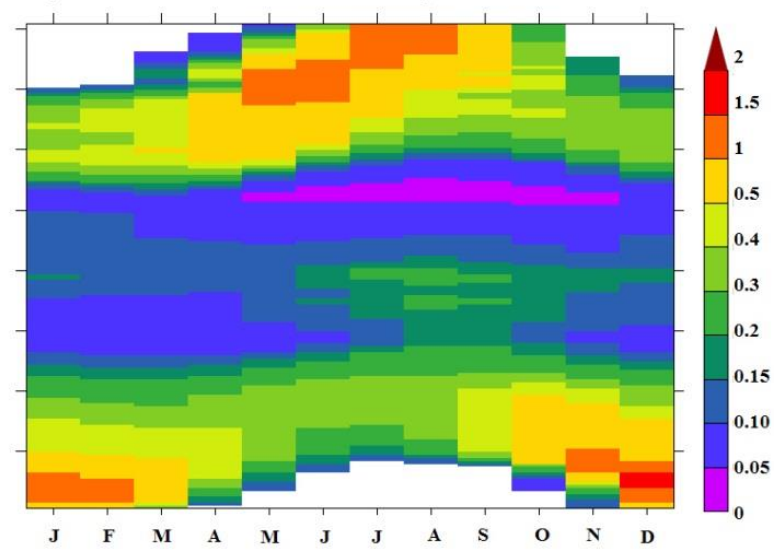

Figure 4. Comparison of remotely sensed observations of chlorophyll (left panels) with simulations performed using the NEMO-PISCES model (right panels). Top panels $(\mathbf{a}, \mathbf{b})$ represent maps of annual mean chlorophyll concentration $\left(\mathrm{mg} \mathrm{m}^{-3}\right)$. Bottom panels $(\mathbf{c}, \mathbf{d})$ represent latitude-time maps of chlorophyll.

and from 30 to $85 \mathrm{pmol} \mathrm{L}^{-1}$ in January). In the photic zone (the first $30 \mathrm{~m}$ below the surface, as implemented in NEMOPISCES), August subsurface OCS concentrations (Fig. 5d) were clearly driven by photo-production (vertical profile of photo-production not shown here). Where the influence of UV-light irradiance is smaller or negligible (below $30 \mathrm{~m}$ in August or in the entire water column in January), OCS concentration profiles are driven by the predominant dark production (vertical profile of the dark production contribution not shown here). Therefore, in these layers, OCS concentrations mostly followed the chlorophyll content profiles. Thus, OCS concentration profiles simulated with NEMO-PISCES in January showed a drop below the mixed layer (below $120 \mathrm{~m}$ ), and became negligible below $200 \mathrm{~m}$. In August, the highest concentrations were found at the surface. A second peak of OCS levels was found around $80 \mathrm{~m}$ depth, where chlorophyll content peaks. Deeper, the OCS concentrations decreased, down to negligible values below $200 \mathrm{~m}$.
OCS concentrations simulated with NEMO-PISCES showed very large values in the few first meters under the surface, averaging 70, 90 or even $270 \mathrm{pmol} \mathrm{L}^{-1}$ in August at the BATS site, depending on the $a_{350}$-chlorophyll relationship used. Some OCS levels measured with buoys during a field campaign in August 1999 at the BATS site peaked at $150 \mathrm{pmol} \mathrm{L}^{-1}$ in the first $3 \mathrm{~m}$ (Cutter et al. 2004), showing a potential to reach such high values. When using the $a_{350}$ formulas derived from the studies of Morel and Gentili (2009) or Preiswerk and Najjar (2000), the simulated vertical profiles of OCS concentrations in the Sargasso Sea in August (Fig. 5d) fall into the range of measured OCS concentrations reported by Cutter et al. (2004). This is however not the case when using the $a_{350}$ based on MODIS Aqua data which lead to the highest simulated OCS concentrations $\left(270 \mathrm{pmol} \mathrm{L}^{-1}\right.$ at the sea surface) and seem to overestimate the natural variability of the OCS concentrations as measured in these waters. 

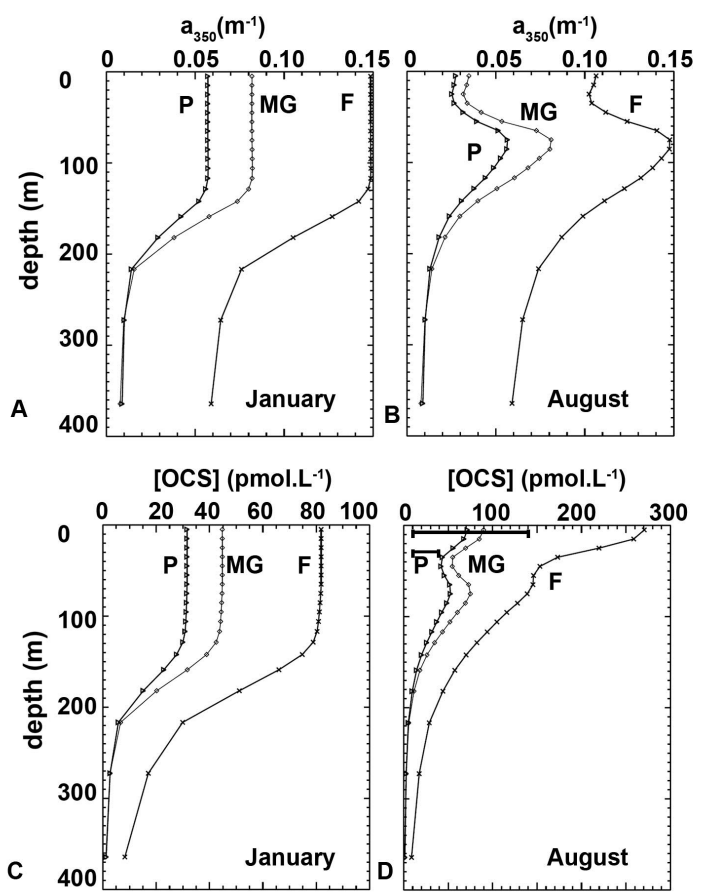

Figure 5. Monthly mean vertical profiles of $a_{350}$ (top row) and OCS concentration (bottom row) in January (left column) and August (right column) simulated by NEMO-PISCES in a 1-D run at the BATS site. The thick lines in (d) cover the range between minimal and maximal values as measured by Cutter et al. (2004). The different $a_{350}$ profiles are calculated using the formulations of Morel and Gentili (2009) (MG, diamonds), Preiswerk and Najjar (2000) (P, triangles) or based on MODIS Aqua data (F, black line). Symbols used on OCS concentration profile on bottom row indicate which $a_{350}$-chlorophyll relationship was used in the simulation.

The lower OCS concentrations in deeper layers reflected the quick removal of OCS by hydrolysis in the model (vertical profile of the hydrolysis contribution not shown here). This behavior fit well with the estimated short lifetime of the OCS molecule in marine waters, ranging between 4 and $13.4 \mathrm{~h}$, according to the models of Elliot et al. (1989) and Radford-Knoery and Cutter (1993), respectively.

\subsection{Spatial and seasonal variability of OCS production and removal processes}

\subsubsection{Surface $a_{350}$ patterns}

Absorption coefficients of CDOM at $350 \mathrm{~nm}\left(a_{350}\right)$ simulated using NEMO-PISCES were evaluated for the different formulations of $a_{350}$ against the annual climatology of $a_{350}$ derived from MODIS Aqua ocean color data as in Fichot and Miller (2010). The MODIS Aqua-derived $a_{350}$ data (Fig. 6a) showed mini mal values in the subtropical gyres, and maximum values in coastal regions and at high latitudes (higher than $45^{\circ} \mathrm{N}$ and $45^{\circ} \mathrm{S}$ ). Note that the MODIS Aqua-derived values should not be considered as direct observations but only as an independent estimate relying on a generic relationship (i.e., a statistical model).

Regions where $a_{350}$ was not accurately modeled also suffered from biases in simulated chlorophyll values. Therefore, the highest $a_{350}$ values observed near the coasts were not represented in NEMO-PISCES due to its limited spatial resolution. Additionally, the simulated chlorophyll maps (thus those of $a_{350}$ as well) showed a higher contrast between low and high latitudes than the SeaWiFS-derived observations (Fig. 4). In tropical regions $\left(30^{\circ} \mathrm{S}-30^{\circ} \mathrm{N}\right)$, especially in the Atlantic Ocean, the Indian Ocean and in the Western Pacific Warm Pool, chlorophyll levels simulated by NEMOPISCES were underestimated by a factor of 2 compared to the SeaWiFS chlorophyll observations (Fig. 4). As these are regions of warm ocean waters favorable to OCS dark production, the consequence might be an underestimation of OCS production in these regions. In regions showing low chlorophyll concentrations, this underestimation translates to an approximate $30 \%$ underestimation of the $a_{350}$ value (depending on the $a_{350}$ formulation used), which directly translates to an equivalent underestimation of OCS dark and photoproduction, since both parameterization linearly depend on $a_{350}$.

Finally, NEMO-PISCES-simulated chlorophyll levels at mid- and high latitudes were similar for northern and southern oceans, with average values around $0.5 \mathrm{mg} \mathrm{m}^{-3}$. However, chlorophyll concentrations deduced from satellite observations showed average mid- and high-latitude values around $0.2 \mathrm{mg} \mathrm{m}^{-3}$ in the Southern Hemisphere and 0.5 to $1 \mathrm{mg} \mathrm{m}^{-3}$ in the Northern Hemisphere. Thus, the NEMOPISCES model overestimated the chlorophyll concentrations by a factor of 2 over most of the mid- and high latitudes of the Southern Hemisphere - especially in the Pacific Ocean and south of Australia (Fig. 4). Therefore, our modeled OCS production in the Southern Hemisphere is likely overestimated.

The different $a_{350}$-chlorophyll relationships used in the present work (Eqs. 2, 3,6) led to simulated values of $a_{350}$ differing by as much as a factor of 3 . The CDOM absorption coefficient values obtained with the formulations of Preiswerk and Najjar (2000) and Morel and Gentili (2009) were similar to the MODIS-derived estimates for low and mid-latitudes (below $60^{\circ} \mathrm{S}$ and $60^{\circ} \mathrm{N}$ ), but largely underestimated at high latitudes in the Northern Hemisphere, with values 2 to 3 times smaller than the MODIS-derived estimates (Fig. 6). Conversely, the formulation presented in this work (Eq. 6) correctly reproduced the observed levels of $a_{350}$ in the northern high latitudes, but clearly overestimated the values for CDOM absorption coefficient at low latitudes and in the Southern Hemisphere: simulated $a_{350}$ values in some subtropical oligotrophic regions reached values 3 to 4 times higher than the MODIS-derived values. 

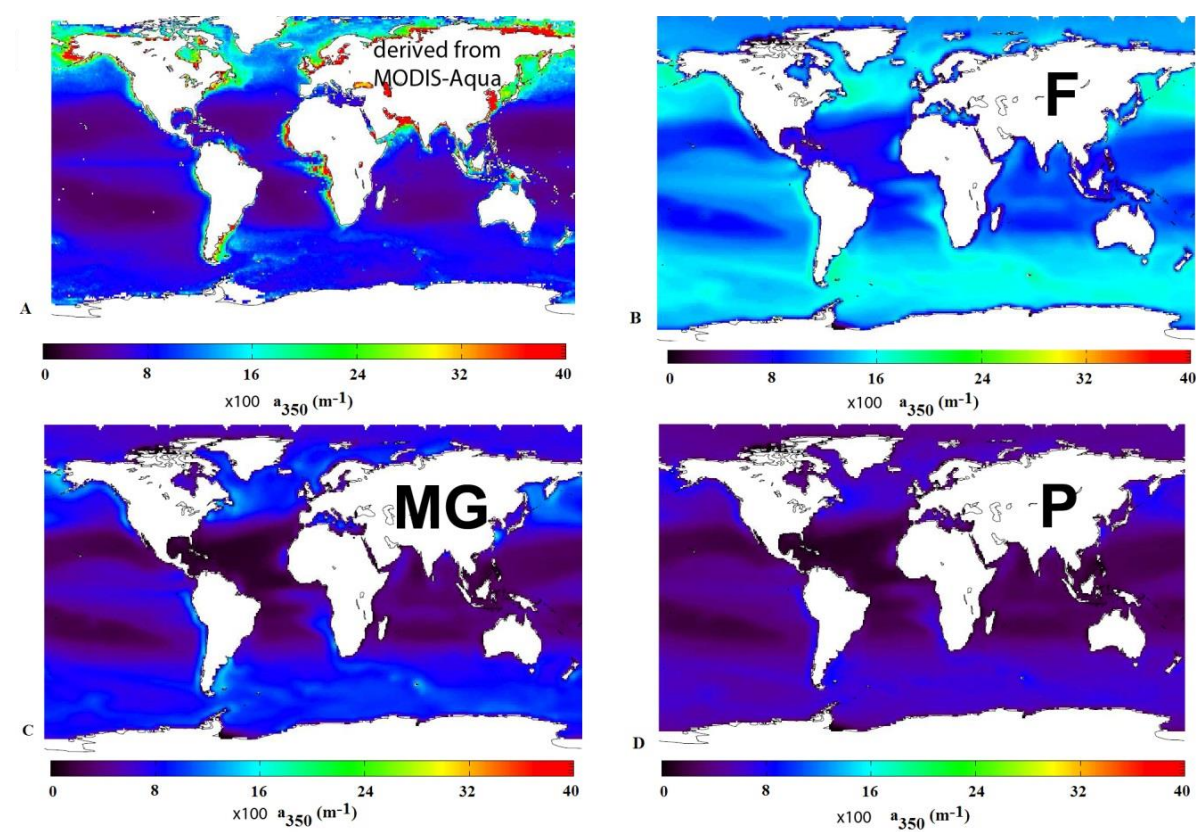

Figure 6. Comparison between annual mean surface absorption coefficient of CDOM at $350 \mathrm{~nm}$ : (a) retrieved from MODIS Aqua satellite data, using SeaUV model (Fichot et al., 2008) and $a_{320} / K_{\mathrm{d} 320}$ ratio from Fichot and Miller (2010), and $a_{350}$ maps simulated with the NEMO-PISCES model using the relationship described in Morel and Gentili (2009) (MG, c), Preiswerk and Najjar (2000) (P, d) and proposed in this work $(\mathrm{F}, \mathbf{b})$.

\subsubsection{Photo-production rates}

In the present study, the $a_{350}$-dependent NEMO-PISCES model and the AQY-dependent photochemical model from Fichot and Miller (2010) were used to provide two independent estimates of OCS photo-production rates. Sensitivity tests were performed on the annual global OCS photoproduction over the entire water column (from the sea surface to the ocean floor). Both models were run with different formulations of $a_{350}$ (NEMO-PISCES model) or using different AQY (Fichot and Miller photochemical model) from the literature.

The AQY estimates used were collected in open ocean environments (Weiss et al., 1995a) and coastal environments (Zepp and Andreae, 1994), respectively. Large uncertainties around AQY estimations depending on the measurement location led to large differences in the estimates of global OCS photo-production. Global OCS photo-production modeled with the Fichot and Miller (2010) model thus ranged from 876 to $5500 \mathrm{GgS} \mathrm{yr}^{-1}$ (Table 1). Extremely high AQY values have been measured on the continental shelf (Cutter et al., 2004), but were not considered appropriate for representing the average global ocean. Using this last value would have led to $37700 \mathrm{GgS} \mathrm{yr}^{-1}$ of OCS global photoproduction, far above observed photo-production levels and other model estimates.

Both the photochemical model from Fichot and Miller (2010) and the NEMO-PISCES model led to similar spatial distributions of OCS photo-production
Table 1. Annual global photo-production of OCS in the entire water column simulated with the NEMO-PISCES model (using the three different $a_{350}$ formulations presented in this paper) or with the photochemical model derived from Fichot and Miller (2010) (FM in the table) (using two different apparent quantum yields estimates). $\mathrm{F}: a_{350}$ parameterization assembled in this work; MG: $a_{350}$ parameterization presented in Morel and Gentili (2009); P: $a_{350}$ parameterization presented in Preiswerk and Najjar (2000).

\begin{tabular}{ll}
\hline $\begin{array}{l}\text { Parameterization } \\
\text { used in the runs }\end{array}$ & $\begin{array}{l}\text { Total photo-produced } \\
\text { OCS in the entire } \\
\text { water column }\left(\mathrm{GgS} \mathrm{yr}^{-1}\right)\end{array}$ \\
\hline $\begin{array}{l}\text { NEMO-PISCES + F } \\
\text { NEMO-PISCES + MG }\end{array}$ & $\begin{array}{l}4540 \\
\text { NEMO-PISCES + P }\end{array}$ \\
$\begin{array}{l}\text { FM + AQY from Weiss } \\
\text { et al. (1995a) }\end{array}$ & 876 \\
$\begin{array}{l}\text { FM + AQY from Zepp } \\
\text { et al. (1994) }\end{array}$ & 5500 \\
\hline
\end{tabular}

(Fig. 7). Indeed, subtropical regions are the major contributors in terms of yearly total photo-production of OCS because the photo-production rates were roughly constant through the entire year, regardless of model used. However, the highest monthly photo-production rates were found in mid-latitude regions $\left(40-60^{\circ} \mathrm{N}\right.$ and $40-60^{\circ} \mathrm{S}$ ) during the period of maximum irradiance, with rates twice as large as the nearly constant rates obtained in tropical regions, 

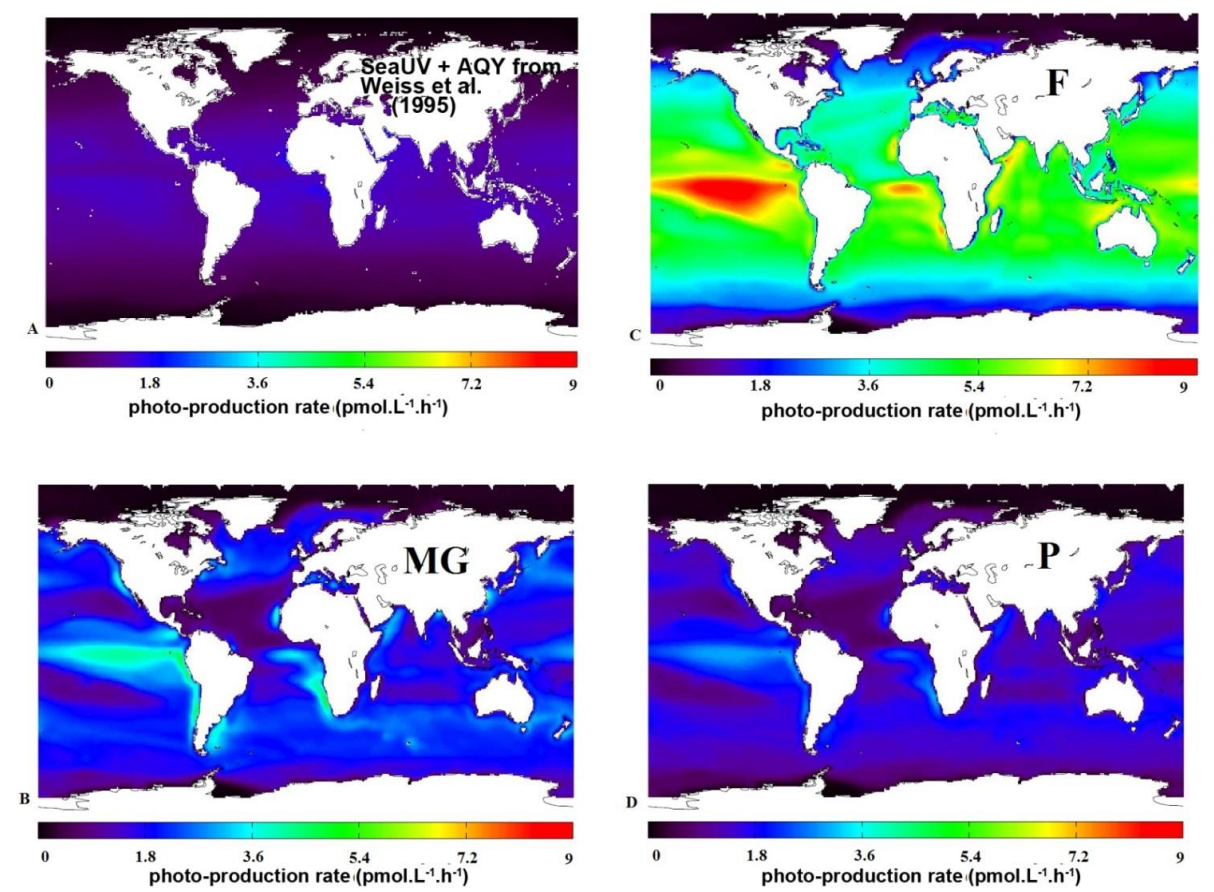

Figure 7. Annual mean photo-production rates integrated over the entire water column simulated with the photochemical model of Fichot and Miller (2010) and using the apparent quantum yield of Weiss et al. (1995a) (a). Comparison with annual mean photo-production rates integrated over the entire water column simulated with the NEMO-PISCES model using $a_{350}$ formulations from Morel and Gentili (2009) (c), Preiswerk and Najjar (2000) (d) and proposed in this study (b).

as can be seen in the time-latitude diagram in Fig. 8a. Depending on the value of the driving parameter for the two models used (AQY or $a_{350}$, respectively), large uncertainties existed over the total quantities of OCS photo-produced. Global photo-production of OCS for the NEMO-PISCES model and the photochemical model from Fichot and Miller (2010) are compared in Table 1. When using the $a_{350}$-based model NEMO-PISCES, the range of the global OCS photo-production was reduced but still large, with estimates between 1390 and $4540 \mathrm{GgS} \mathrm{yr}^{-1}$ depending on which formulation was chosen to calculate $a_{350}$. These values were in rather good agreement with the range obtained with the AQY-based photochemical model from Fichot and Miller (2010).

The photochemical model from Fichot and Miller and NEMO-PISCES showed lower OCS photo-production rates than in situ measurements, irrespective of the $a_{350}$ formulation. For instance, Cutter et al. (2004) estimated August photo-production rates of up to 10 or $15 \mathrm{pmol} \mathrm{L}^{-1} \mathrm{~h}^{-1}$ in the Sargasso Sea, which is above the values of 4 to 9 pmol $\mathrm{L}^{-1} \mathrm{~h}^{-1}$ obtained by running the NEMO-PISCES model at the same location (with implemented Eqs. (3) and (6), respectively) (Fig. 7).
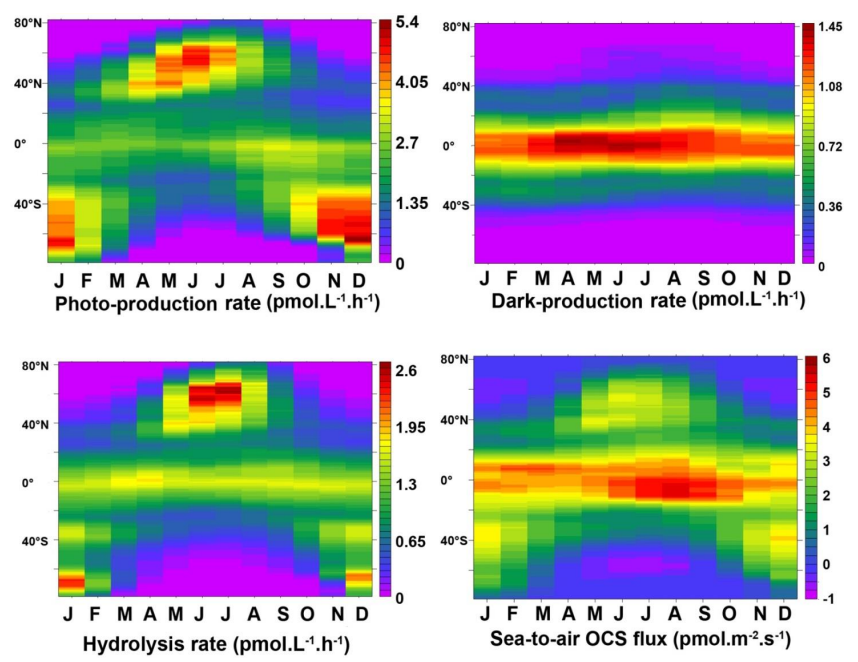

Figure 8. Latitude-time plots comparing relative importance of individual processes for OCS production (top row) and removal (bottom row) in NEMO-PISCES surface layer. Sea-air exchanges are displayed in the bottom right panel are displayed with positive fluxes when OCS is outgassed into the atmosphere. All runs were performed using the Morel and Gentili (2009) formulation to calculate $a_{350}$ and the Elliott et al. (1989) formulation of hydrolysis constant. 


\subsubsection{Dark production rates}

Dark production is a linear function of $a_{350}$ (Eq. 8). However, temperature is the main driver of global OCS dark production as simulated by NEMO-PISCES. The time-latitude representation of dark production rates (Fig. 8b) show that the maximum values were located at low latitudes, in warm marine waters, despite the fact that these regions correspond to the lowest $a_{350}$ values (Fig. 6). The dark production rates in these regions remained relatively constant throughout the year. On the contrary, chlorophyll-rich waters at higher latitudes, leading to higher $a_{350}$ values (Fig. 6), corresponding to colder marine waters and thus limited dark production rates (due to the temperature dependency in Eq. 8).

Measurements from Von Hobe et al. (2001) at the BATS site showed dark production rates of 1 to $1.5 \mathrm{pmol} \mathrm{L}^{-1} \mathrm{~h}^{-1}$. NEMO-PISCES results showed a very good agreement with this data, with rates of $0.8 \mathrm{pmol} \mathrm{L}^{-1} \mathrm{~h}^{-1}$ in August at the BATS site (not shown). In the study of Cutter et al. (2004), calculated dark production rates reached $4 \mathrm{pmol} \mathrm{L}^{-1} \mathrm{~h}^{-1}$ in August, significantly above the simulated range by NEMOPISCES. Von Hobe et al. (2001) estimated that dark production produces around $50 \%$ of OCS at these low latitudes. In the NEMO-PISCES model, dark production only represented $34 \%$ of the OCS produced at low latitudes, and $66 \%$ of OCS is photo-produced.

\subsubsection{Hydrolysis rates}

Figure 2 presents the hydrolysis reaction constant as a function of temperature for a given $\mathrm{pH}$, as given by the Kamyshny et al. (2003) and Elliott et al. (1989) formulations. Both formulations relate the OCS hydrolysis to the OCS concentration and to the seawater $\mathrm{pH}$ (Reactions R1a and R1b). At a given $\mathrm{pH}$, the difference between the two formulations led to a $50 \%$ difference in the hydrolysis constant for seawater temperatures above $12{ }^{\circ} \mathrm{C}$ (Fig. 2). A comparison between timelatitude maps of the hydrolysis rate (Fig. 8c) and the OCS concentration (in Fig. S1 in the Supplement) suggests that OCS hydrolysis rates in NEMO-PISCES are largely driven by OCS concentrations. These spatiotemporal variation patterns only slightly differ around the Equator, where marine waters are somewhat less alkaline, which leads to a limitation of the OCS hydrolysis rate through $\mathrm{pH}$ influence. Simulations run with two different hydrolysis parameterizations (based on Reactions R1a and R1b) provide global OCS emissions diverging by a factor of 2.5 (see Fig. 9).

\subsubsection{Evaluation of surface concentration patterns}

Maps of annual mean surface OCS concentration patterns at sea surface simulated with NEMO-PISCES are presented in Fig. 10 (right column). NEMO-PISCES simulations produced maximum annual mean OCS levels in equatorial and sub-tropical regions, where dark production was maximal and photo-production was constantly active. In low-latitude marine waters, OCS concentrations remained nearly constant throughout the year (Fig. S1 and Fig. 10). However, the model showed a strong seasonal variability of OCS concentrations for mid- and high latitudes, with roughly a factor of 10 difference between maximal and minimal OCS concentration levels reached throughout the year. These spatial distributions and the intra-annual variation amplitudes were relatively independent of the formulation used in NEMOPISCES to calculate $a_{350}$.

Modeled OCS concentrations were evaluated against observational data available in the literature. OCS concentrations measured near European shores and estuarine regions over the year showed large spatial and temporal variability (Uher, 2006). The few measured OCS concentrations in estuarine regions were close to $250 \mathrm{pmol} \mathrm{L}^{-1}$ in winter and $430 \mathrm{pmol} \mathrm{L}^{-1}$ in summer, while smaller values were measured near shores from $40 \mathrm{pmol} \mathrm{L}^{-1}$ in winter to $100 \mathrm{pmol} \mathrm{L}^{-1}$ in summer. Von Hobe et al. (2003) also measured summer OCS surface maximum levels of $120 \mathrm{pmol} \mathrm{L}^{-1}$ in an upwelling region near the Portuguese coast. When using the MODIS Aqua-based $a_{350}$ formulation (Eq. 6) which gives the best representation of $a_{350}$ in the region (Fig. 6), simulated OCS nearshore concentrations only reached values from $30 \mathrm{pmol} \mathrm{L}^{-1}$ in winter to $100 \mathrm{pmol} \mathrm{L}^{-1}$ in summer (Fig. 10). NEMO-PISCES matches correctly the seasonal amplitude of OCS concentrations measured in these areas and represents quite accurately the absolute values measured near the shores. However, as expected, the lack of resolution of the model translates into an underestimation of the estuarine concentrations.

As shown in the comparison done in the study of von Hobe et al. (2003), the reproduction of the OCS depth profiles by their models was generally less accurate than that of surface data because the models were tuned to fit the surface concentrations. In our study, the model was not tuned to fit surface or depth concentrations. As NEMO-PISCES provides gridded monthly mean concentrations of OCS on the entire water column, monthly mean concentrations of OCS data series should, ideally, be used to evaluate the global simulations.

Unfortunately, a global database of sea surface OCS measurements and a procedure to calculate sea surface OCS as a function of latitude, longitude and month are not available in the literature as, for example, for DMS (e.g., Kettle et al., 1999; Lana et al., 2011). The assemblage of a global OCS database was not achievable in the framework of this project. The evaluation of the modeled oceanic OCS concentrations that had been carried out is not fully satisfactory because we implicitly chose to compare modeled monthly mean concentrations and discrete measurements.

With these caveats in mind, 150 OCS measurements classified according to location, date and depth were gathered from the literature (Weiss et al., 1995a; Ulshöfer et al., 1996; Cutter et al., 2004; Von Hobe et al., 2001, 2003) and compared with the outputs from the model run with its "standard" 


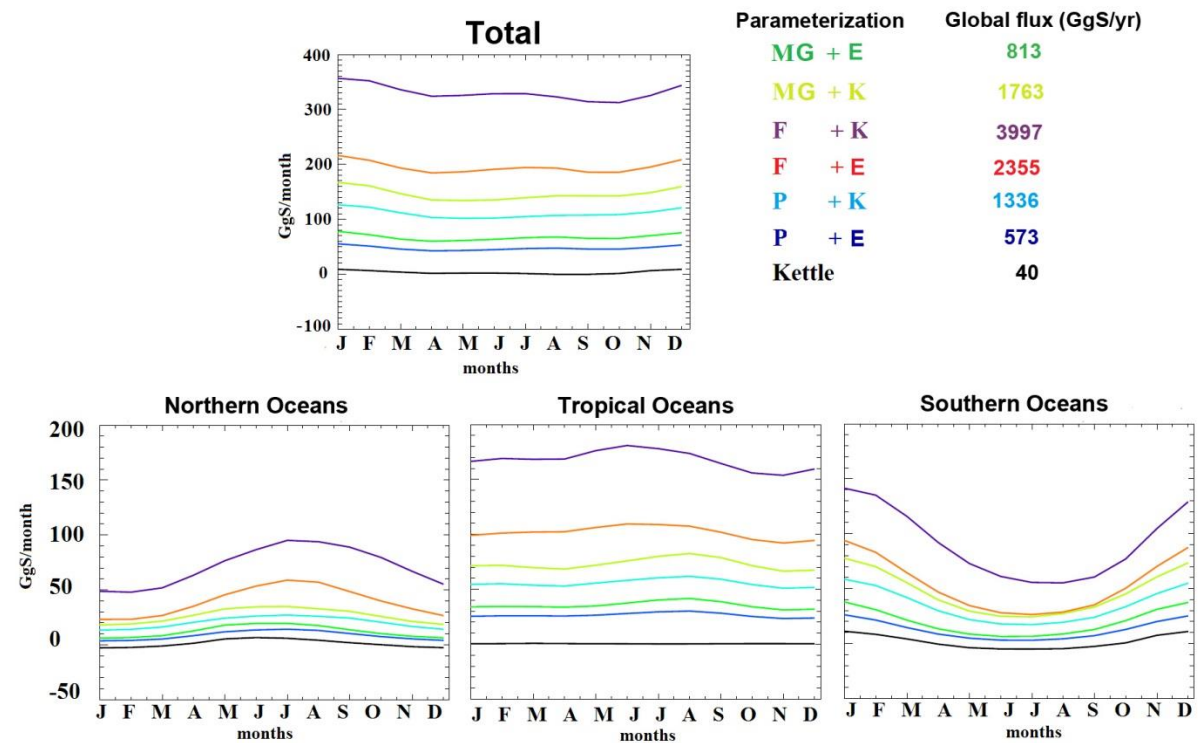

Figure 9. Global and regional monthly mean sea-air fluxes for six different parameterizations of the NEMO-PISCES model. Kettle et al. (2002) (black line) is shown as a reference. Each colored line represents a set of parameters: the first initial(s) refers to the equation used to calculate the UV absorption coefficient of CDOM at $350 \mathrm{~nm}$ and the second initial refers to the hydrolysis constant formulation. Global fluxes on top row, northern oceans $\left(30^{\circ}-90^{\circ} \mathrm{N}\right.$, bottom left), tropical region $\left(30^{\circ} \mathrm{S}-30^{\circ} \mathrm{N}\right.$, bottom center), southern oceans $\left(30^{\circ}-90^{\circ} \mathrm{S}\right.$, bottom right). F: $a_{350}$ relationship assembled in this study; MG: $a_{350}$ relationship from Morel and Gentili (2009); P: $a_{350}$ relationship from Preiswerk and Najjar (2000); E: hydrolysis constant from Elliott et al. (1989); K: hydrolysis constant from Kamyshny et al. (2003).
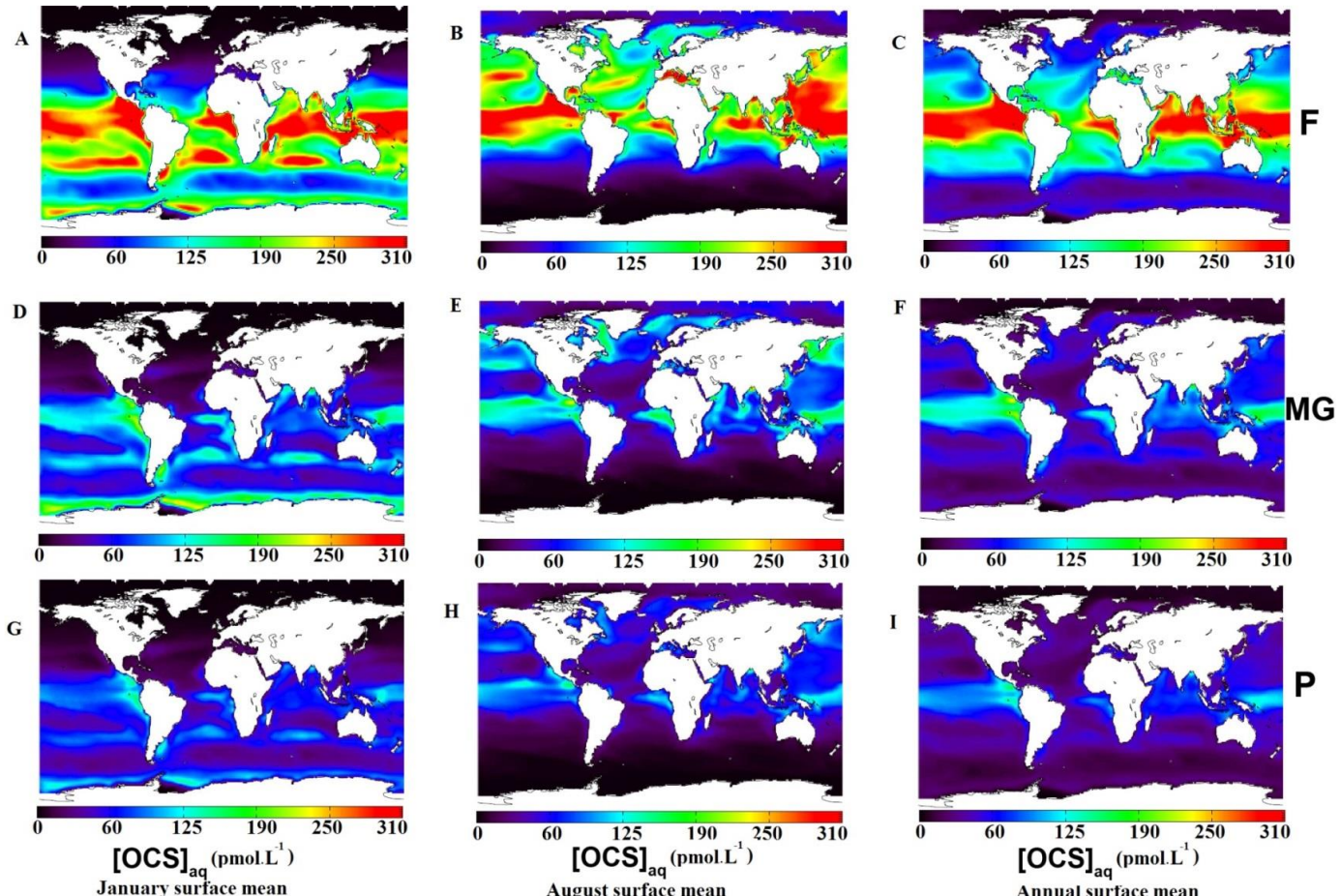

Figure 10. Monthly mean surface OCS concentrations for January (left column), August (central column) and annual mean (right column) simulated with NEMO-PISCES. The three simulations differ in the relationship used to calculate $a_{350}$ from chlorophyll: MODIS Aquaderived, proposed in this study (F, upper row), from Preiswerk and Najjar (2000) (P, central row) and Morel and Gentili (2009) (MG, lower row). 
parameterization, as described in the discussion section. The results are displayed in Fig. S2 and show that the outputs of the model generally overestimate the measured concentrations by a factor of 2 to 4 at the sea surface (first $10 \mathrm{~m}$, A), especially at sites where low concentrations were measured. In seawaters with high OCS concentration measurements (higher than $100 \mathrm{pmol} \mathrm{L}^{-1}$ ), the corresponding simulated concentrations were generally underestimated, up to a factor of 2. A better agreement between modeled and observed concentrations is found with the subsurface data (below $10 \mathrm{~m}, \mathrm{~B})$.

This model-data comparison suggests that simulated OCS concentrations might be overestimated in a significant way in surface waters, which might lead to an overestimation of the simulated OCS outgassing fluxes (up to a factor of 2 to 4). However, the limited spatial (many measurements were done around $40^{\circ} \mathrm{N}$ ) and temporal (many measurements in July and August) distribution of the measurements severely reduced the possibility for an exhaustive model validation and for the identification of concentration biases in the model. Furthermore, a large range of concentrations were measured even for sites close in latitude and for measurements realized around the same period of the year. Finally, this overestimation might also compensate for the underestimation in the OCS production in shallow water, since the model is lacking an exhaustive representation of the estuarine regions.

The formulation used to calculate $a_{350}$ values did not affect the global spatial distribution of OCS concentrations, but it largely influenced the absolute value of the simulated OCS concentrations. For instance, maximal OCS concentrations in tropical sub-surface waters were estimated close to $300 \mathrm{pmol} \mathrm{L}^{-1}$ with the MODIS Aqua-based $a_{350}$ formulation (Eq. 6), while estimates based on Morel and Gentili (2009) and Preiswerk and Najjar (2000) only reached one-half (onethird, respectively) of these modeled maximal concentrations (Fig. 10). Note that the formulation of Morel and Gentili (2009) led to results that were in better agreement with the campaign measurements described in Sect. 3.2.2 (Cutter et al., 2004; von Hobe et al., 2001).

\section{Discussion}

The limited number of studies which have attempted to quantify OCS production and removal processes individually have yielded widely differing results. Several parameterizations for each process have been proposed and each parameterization remains poorly constrained. In this section we present our "best guess" formulations for the individual OCS-related processes in the NEMO-PISCES model.

Measurement campaigns used to determine dark production functions are particularly scarce. The dark production parameterization that we used is related to the CDOM absorption coefficient at $350 \mathrm{~nm}$ as a parameterization of the link with organic matter content and biological activity in marine environments. However, there is no rationale for dark production to be dependent of colored organic matter content (CDOM, chlorophyll) since this process occurs at times when no light is available.

In a rare example of an observation-based dark production parameterization effort, von Hobe et al. (2003) used an experimental setup that allowed them to equate the OCS dark production rate to the hydrolysis rate, and thus expressed the first as a function of a measurement of the latter. In their estimate of the hydrolysis rate, von Hobe et al. (2003) used the Elliott et al. (1989) formulation for the OCS hydrolysis constant. Thus, our use of the von Hobe et al. (2003) dark production parameterization is consistent with the choice of the Elliott et al. (1989) parameterization for OCS hydrolysis.

As previously described, simulated $a_{350}$ values can be far from the observed values in warm water regions depending on the $a_{350}$ formulation used (Fig. 6). This potentially leads to the largest errors in the dark production rate estimates. In this context, we have found the Morel and Gentili (2009) $a_{350}$ parameterization to perform best when evaluated against $a_{350}$ values derived from MODIS Aqua data at low latitudes, as well as at high latitudes in the Southern Hemisphere (Sect. 3.3.1). This formulation may, however, lead to an underestimation of $a_{350}$ at high latitudes in Northern Hemisphere.

We have chosen the Uher and Andreae (1997) formulation for photoproduction associated with the Morel and Gentili parameterization for $a_{350}$ (Eq. 2) and the Elliott formulation for the hydrolysis constant as the standard parameterizations for OCS processes in NEMO-PISCES, based on the arguments above. Time-latitude diagrams for photo- and dark production, hydrolysis and surface OCS fluxes using these parameterizations are represented in Fig. 8. The timelatitude diagram representing the surface layer OCS concentration with the same settings is shown in Fig. S1.

The standard run of NEMO-PISCES suggests most OCS is produced photochemically. Even at low latitudes, where warm water regions favor dark production of OCS, photoproduction represents $66 \%$ of OCS production pathway (Fig. 8). In this simulation, low latitudes are the only regions where dark production rates compensate for hydrolysis removal of OCS. The highest annual mean OCS concentrations modeled using best guess parameterizations range between 100 and $200 \mathrm{pmol} \mathrm{L}^{-1}$ and are encountered around the Equator, especially in central and eastern Pacific Ocean. At mid- and high latitudes, simulated annual mean OCS concentrations are included between 10 and $60 \mathrm{pmol} \mathrm{L}^{-1}$. These regions show higher seasonal amplitude in OCS concentrations, especially around $60^{\circ} \mathrm{N}$ and $40^{\circ} \mathrm{S}$, where periods of irradiance maxima (minima) lead to simulated OCS concentrations of $150 \mathrm{pmol} \mathrm{L}^{-1}\left(10 \mathrm{pmol} \mathrm{L}^{-1}\right)$. In these regions, simulated concentrations are largely consistent with in situ measurements from Cutter et al. (2004) and Von Hobe et al. (2003). 
Surface OCS concentrations simulated by NEMOPISCES are the main driver of the model's sea-air OCS fluxes (Fig. 8d and Fig. S1). The regions with the highest sea surface OCS concentrations (tropics and mid-latitudes during maximal irradiance seasons) are the regions emitting the largest quantities of OCS. Multiple measurement campaigns (Rasmussen et al., 1982; Ferek and Andreae, 1984; Uher, 2006) have shown that coastal environments can have OCS concentrations 5 to 10 times higher than those measured at the surface of open ocean waters in oligotrophic regions. As shown in Fig. 6, MODIS-derived $a_{350}$ reach maximal values along shores but the NEMO-PISCES model does not represent these localized maxima due to the poor model resolution in these regions. These narrow areas have an important potential in OCS production and show underestimated OCS concentrations in NEMO-PISCES.

Air-sea exchange of OCS is also enhanced by warm surface waters and strong winds (Eq. 12). Both variables have a noticeable impact on the simulated OCS surface fluxes, especially at low latitudes. In fact, NEMO-PISCES simulations show the highest OCS emissions around the Equator even if some mid- and high-latitude oceanic regions show higher OCS sea surface concentrations for some periods of the year: OCS outgassing rates in July along the Equator are twice as important as outgassing taking place in northern mid-latitudes in the same period (Fig. 8d), despite the midlatitudes showing surface OCS concentrations $60 \%$ higher than those simulated around the Equator.

We have investigated the sensitivity of the sea-air fluxes to the parameterizations of OCS production and removal processes. Global and regional annual sea-air OCS fluxes obtained in these tests are summarized in Fig. 9. Simulated fluxes by Kettle et al. (2002) are also represented in Fig. 9 (black line) for comparison. While the different parameterization choices lead to a large spread in the simulated OCS fluxes into the atmosphere, NEMO-PISCES consistently produces higher estimates of the global sea-air OCS fluxes than the ones previously estimated by Kettle et al. (2002). Total emitted OCS simulated using the best guess parameterization of NEMO-PISCES reaches $813 \mathrm{GgS} \mathrm{yr}^{-1}$, far above the modeled direct source of $40 \mathrm{GgS} \mathrm{yr}^{-1}$ from Kettle et al. (2002) and consistent with the revised global oceanic flux based on atmospheric measurements and a model for leaf uptake, proposed by Berry et al. (2013) (736 GgS yr $^{-1}$ )(Table 2). Extrapolations of measurements carried out in the Mediterranean Sea and the Indian Ocean by Mihalopoulos et al. (1992) led to an independent estimate of $213 \mathrm{GgS} \mathrm{yr}^{-1}$, markedly lower than the mean annual global flux simulated with NEMO-PISCES. Kettle et al. (2002) described the global direct exchange of OCS between the ocean and the atmosphere as highly uncertain, and pointed out the fact that in some of their simulations, some regions of the ocean behaved like sinks of atmospheric OCS at certain periods of the year. Some regions at extreme high latitudes also act like sinks of atmospheric OCS in NEMO-PISCES for certain periods of the year (Fig. 8d).

The different parameterizations available for the different processes presented in this paper lead to different global flux estimates, ranging from $573 \mathrm{GgS} \mathrm{yr}^{-1}$ (when using the CDOM absorption coefficient values obtained with the formulations of Preiswerk and Najjar (2000) using the MODISderived $a_{350}$ and the lower values of the Kamyshny-based hydrolysis constant). Our best guess parameterization of NEMO-PISCES shows the best agreement with the in situ evaluation of the individual processes, and stands in the lower part of the range of OCS direct annual emissions by ocean at a global scale.

Changing the parameterization also changes the seasonal amplitude of the simulated OCS flux by up to a factor of 5 for northern and southern hemispheric oceans but no significant change is noticeable in the seasonal amplitude of OCS fluxes in the tropical region.

Recent efforts to constrain global OCS fluxes have led to a growing number of measurements and consequent revisions of soil and vegetation uptake estimates. Multiple recent studies have suggested that soil and vegetation uptakes were underestimated in the new assessments of the global OCS cycle and have suggested a global sink for both of up to $1000 \mathrm{GgS} \mathrm{yr}^{-1}$ (Berry et al., 2013; Suntharalingam et al., 2008), much larger than the estimates of approximately $300 \mathrm{GgS} \mathrm{yr}^{-1}$ by Kettle et al. (2002). Knowing that atmospheric OCS levels show no trend over the last 2 decades (Montzka et al., 2007), the global cycle of OCS is expected to be balanced on a global scale. In order to compensate re-estimated sinks based on a mechanistic description of leaf OCS uptake (using SIB3 land surface model), Berry et al. (2013) have suggested that the ocean provides the missing source. Using a simple inversion approach to optimize the oceanic missing source, given known land natural and anthropogenic fluxes, the authors evaluated that the ocean should emit $736 \mathrm{GgS} \mathrm{yr}^{-1}$. Moreover, the best fit optimization used by the authors revealed that the missing source should be concentrated over the low latitudes in order to best fit the atmospheric data recorded at NOAA stations.

Using our best guess parameterization for NEMO-PISCES leads to relatively constant global OCS outgassing throughout the year, with a seasonal amplitude of only $10 \%$. Tropical regions $\left(30^{\circ} \mathrm{S}-30^{\circ} \mathrm{N}\right)$ emit the major part of the OCS, and represent up to $45 \%$ of the total emitted OCS into the atmosphere. Tropical exchanges show almost no variation throughout the year. Northern and southern oceanic regions at mid- and high latitudes (higher than $30^{\circ} \mathrm{N}$ and $30^{\circ} \mathrm{S}$, respectively) contribute to 20 and $35 \%$, respectively, of the OCS global flux in the atmosphere each year (Fig. S3).

Despite the consistency in terms of global OCS fluxes quantities and spatial distribution between best guess parameterizations of NEMO-PISCES and indirect oceanic source estimates from Berry et al. (2013), the simulated outgassing using NEMO-PISCES shows a large envelope when using 
Table 2. Yearly global OCS flux emitted from ocean to the atmosphere (in $\mathrm{GgS} \mathrm{yr}^{-1}$ ) depending on the different parameterizations presented in previous work and in this work. F: $a_{350}$ parameterization presented in this work; MG: $a_{350}$ parameterization presented in Morel and Gentili (2009); P: $a_{350}$ parameterization presented in Preiswerk and Najjar (2000).

\begin{tabular}{|c|c|c|c|}
\hline Study & \multicolumn{2}{|c|}{ Method } & Annual flux $\left(\mathrm{GgS} \mathrm{yr}^{-1}\right)$ \\
\hline \multicolumn{4}{|c|}{ Interpolation of observations } \\
\hline Chin and Davis (1993) & \multicolumn{2}{|c|}{ sea surface OCS supersaturation ratios ${ }^{\mathrm{a}}$} & 200 to 900 \\
\hline Watts (2000) & \multicolumn{2}{|c|}{ OCS surface concentration ${ }^{\mathrm{b}}$} & $300^{*}$ \\
\hline \multicolumn{4}{|c|}{ Forward modeling } \\
\hline & $\mathrm{AQY} / \mathrm{a}_{350}$ & hydrolysis constant & \\
\hline Kettle et al. $(2002)^{\mathrm{c}}$ & AQY & Elliott et al. (1989) & $40^{* *}$ \\
\hline Berry et al. (2013) ${ }^{d}$ & from Kettle et al. (2002) & from Kettle et al. (2002) & 736 \\
\hline This work standard run & $a_{350}$ from MG & Elliott et al. (1989) & 813 \\
\hline \multicolumn{4}{|c|}{$\begin{array}{l}\text { a Sea surface OCS supersaturation ratios from open oceans, upwelling zones and coastal regions; }{ }^{\mathrm{b}} \text { OCS surface concentration from } \\
\text { estuarine, coastal and open ocean environments; }{ }^{\mathrm{c}} \text { based on UV irradiance and apparent quantum yields from the literature. Lowest and } \\
\text { highest boundaries of the estimates correspond to the lowest and highest AQY used. }{ }^{\mathrm{d}} 136 \mathrm{GgS} \mathrm{yr}^{-1} \text { taken from Kettle upper estimate. } \\
\text { Added source of } 600 \mathrm{GgS} \mathrm{yr}^{-1} \text { necessary to equilibrate the global budget. }{ }^{*} 100 \mathrm{GgS} \mathrm{yr}^{-1} \text { from open ocean and } 200 \mathrm{GgS} \mathrm{yr}^{-1} \text { from coastal } \\
\text { shores; }{ }^{* *} \text { uncertainty range: between }-110 \mathrm{GgS} \mathrm{yr}^{-1} \text { and }+190 \mathrm{GgS} \mathrm{yr}^{-1} \text {. }\end{array}$} \\
\hline
\end{tabular}

the different possible parameterizations. Most of them lead to much larger global flux estimates than previous studies, ranging between 573 and $3997 \mathrm{GgS} \mathrm{yr}^{-1}$. Higher estimates for OCS fluxes with NEMO-PISCES result from using the hydrolysis constant from Kamyshny et al. (2003) or $a_{350}$ calculation proposed in this present work. Kamyshny-based hydrolysis constant is not homogeneous with the choice of an Elliot-based hydrolysis constant used to determinate OCS dark production by von Hobe et al. (2001), as implemented in NEMO-PISCES. Moreover, calculation of $a_{350}$ proposed in this work was demonstrated to lead to large overestimations of the $a_{350}$ values compared with the observational data. Both parameterizations lead to very large estimates of OCS fluxes in the atmosphere, which are not likely since they would lead to a highly unbalanced atmospheric OCS budget.

\section{Conclusions}

At a global scale, the ocean is supposed to be the largest direct and indirect source of atmospheric OCS. Recent studies (Suntharalingam et al., 2008; Berry et al., 2013) pointed out the need to reevaluate the global OCS sinks, signaling a possible underestimation in previous assessments. There is currently no trend in the atmospheric levels of OCS (Montzka et al., 2007); thus, increased sinks have to be compensated by a source, currently missing from the global OCS budget. The recent inversion study of Berry et al. (2013) and previous Atmospheric Chemistry Experiment ACE observational analysis of Barkley et al. (2008) have suggested that a large part of this missing source should be ocean outgassing at low latitudes.

Previous studies of the OCS production and removal processes in the ocean have only led to poor constraint of the potential global sea-air fluxes. Moreover, numerical simulations have led to relatively small modeled global fluxes of OCS outgassed to the atmosphere. In this study we have selected different parameterizations for the most important OCS production and removal processes, which we then implemented in the 3-D NEMO-PISCES ocean model.

Simulated fluxes with this model showed a potential for large global OCS fluxes, with our best guess simulation reaching a net emission of OCS of up to $800 \mathrm{GgS} \mathrm{yr}^{-1}$, much larger than previous estimated ranges. Moreover, the resulting spatial distribution of theses fluxes supports the assumed key role of tropical regions, where warm marine waters can produce high levels of OCS with only minimal organic matter. Our modeled ocean-atmosphere OCS fluxes were concentrated in the equatorial and subtropical regions, which accounted for half of the global OCS outgassing to the atmosphere. This result is in good agreement with the necessary distribution of the missing oceanic source of OCS that would be consistent with the atmospheric OCS concentration gradients (north-south for instance), measured at different stations of the NOAA network. The uncertainties around OCS fluxes, however, will remain very large until a wide array of measurements focusing on the individual processes is available to accurately calibrate the relative importance of each marine OCS production and removal process.

\section{The Supplement related to this article is available online at doi:10.5194/acp-15-2295-2015-supplement.}


Author contributions. S. Belviso and P. Peylin designed the experiments. T. Launois did the bibliography research for process parameterizations and developed the NEMO-PISCES specific OCS module code and performed the simulations with help from L. Bopp. C. Fichot ran tests with the SeaUV model that he developed, allowing comparison of OCS photo-production rates with the results obtained with NEMO-PISCES. T. Launois prepared the manuscript with contributions from all co-authors.

Acknowledgements. The authors wish to thank Elliott Campbell who shared simulation results from Kettle et al. (2002), allowing for the comparisons done in this work. We also thank Alina Gainusa-Bogdan for improving the manuscript.

Edited by: M. Palm

\section{References}

Aumont, O. and Bopp, L.: Globalizing results from ocean in situ iron fertilization studies, Global Biogeochem. Cy., 20, GB2017, doi:10.1029/2005GB002591, 2006.

Barkley, M. P., Palmer, P. I., Boone, C. D., Bernath, P. F., and Suntharalingam, P.: Global distributions of carbonyl sulfide in the upper troposphere and stratosphere, Geophys. Res. Lett., 35, L14810, doi:10.1029/2008GL034270, 2008.

Barnes, I., Becker, K. H., and Patroescu, I.: The tropospheric oxidation of dimethyl sulfide: A new source of carbonyl sulfide, Geophys. Res. Lett., 21, 2389-2392, 1997.

Berry, J., Wolf, A., Campbell, J. E., Baker, I., Blake, N., Blake, D., and Zhu, Z.: A coupled model of the global cycles of carbonyl sulfide and $\mathrm{CO} 2$ : A possible new window on the carbon cycle, J. Geophys. Res.-Biogeo., 118, 842-852, 2013.

Bricaud, A., Babin, M., Morel, A., and Claustre, H.: Variability in the chlorophyll-specific absorption coefficients of natural phytoplankton: Analysis and parameterization, J. Geophys. Res.Oceans., 100, 13321-13332, 1995.

Brühl, C., Lelieveld, J., Crutzen, P. J., and Tost, H.: The role of carbonyl sulphide as a source of stratospheric sulphate aerosol and its impact on climate, Atmos. Chem. Phys., 12, 1239-1253, doi:10.5194/acp-12-1239-2012, 2012.

Campbell, J. E., Carmichael, G. R., Chai, T., Mena-Carrasco, M., Tang, Y., Blake, D. R., and Stanier, C. O.: Photosynthetic control of atmospheric carbonyl sulfide during the growing season, Science, 322, 1085-1088, 2008.

Chin, M. and Davis, D. D.: A reanalysis of carbonyl sulfide as a source of stratospheric background sulfur aerosol, J. Geophys. Res.-Oc. Atmos., 100, 8993-9005, 1993.

Cutter, G. A., Cutter, L. S., and Filippino, K. C.: Sources and cycling of carbonyl sulfide in the Sargasso Sea, Limnol. Oceanogr., 49, 555-565, 2004.

Elliott, S., Lu, E., and Rowland, F. S.: Rates and mechanisms for the hydrolysis of carbonyl sulfide in natural waters, Environ. Sci. Technol., 23, 458-461, 1989.

Farmer, C. T., Moore, C. A., Zika, R. G., and Sikorski, R. J.: Effects of low and high Orinoco river flow on the underwater light field of the Eastern Caribbean Basin, J. Geophys. Res., 98, 2279 $2288,1993$.
Ferek, R. J. and Andreae, M. O.: Photochemical production of carbonyl sulphide in marine surface waters, Global Biogeochem. Cy., 6, 175-183, 1984.

Fichot, C. G. and Miller, W. L.: An approach to quantify depthresolved marine photochemical fluxes using remote sensing: Application to carbon monoxide (CO) photoproduction, Remote Sens. Environ., 114, 1363-1377, 2010.

Fichot, C. G., Sathyendranath, S., and Miller, W. L.: SeaUV and SeaUVC: Algorithms for the retrieval of UV/Visible diffuse attenuation coefficients from ocean color, Remote Sens. Environ., 112, 1584-1602, 2008.

Flöck, O. R., Andreae, M. O., and Dräger, M.: Environmentally relevant precursors of carbonyl sulfide in aquatic systems, Mar. Chem., 59, 71-85, 1997.

Garver, S. A. and Siegel, D. A.: Global application of the UCSB non-linear inherent optical property in version model, poster presented at SeaWiFS Science Team Meeting, U.S. Global Change Research Program, Baltimore, Md., 6-8 January, 1998.

Johnson, J. E. and Harrison, H.: Carbonyl sulfide concentrations in the surface waters and above the Pacific Ocean, J. Geophys. Res.Oc. Atmos., 91, 7883-7888, 1986.

Kamyshny, A., Goifman, A., Rizkov, D., and Lev, O.: Formation of carbonyl sulfide by the reaction of carbon monoxide and inorganic polysulfides, Environ. Sci. Technol., 37, 1865-1872, 2003.

Kettle, A. J., Andreae, M. O., Amouroux, D., Andreae, T. W., Bates, T. S., Berresheim, H., Bingemer, H., Boniforti, R., Curran, M. A J., DiTullio, G. R., Helas, G., Jones, G. B., Keller, M. D., Kiene, R. P., Leck, C., Levasseur, M., Malin, G., Maspero, M., Matrai, P., McTaggart, A. R., Mihalopoulos, N., Nguyen, B. C., Novo, A., Putaud, J. P., Rapsomanikis, S., Roberts, G., Schebeske, G., Sharma, S., Simó, R., Staubes, R., Turner, S., and Uher, G.: A global database of sea surface dimethylsulfide (DMS) measurements and a procedure to predict sea surface DMS as a function of latitude, longitude, and month, Global Biogeochem. Cy., 13, 399-444, doi:10.1029/1999GB900004, 1999.

Kettle, A. J., Kuhn, U., von Hobe, M., Kesselmeier, J., Liss, P. S., and Andreae, M. O.: Comparing forward and inverse models to estimate the seasonal variation of hemisphere-integrated fluxes of carbonyl sulfide, Atmos. Chem. Phys., 2, 343-361, doi:10.5194/acp-2-343-2002, 2002.

Kloster, S., Feichter, J., Maier-Reimer, E., Six, K. D., Stier, P., and Wetzel, P.: DMS cycle in the marine ocean-atmosphere system a global model study, Biogeosciences, 3, 29-51, doi:10.5194/bg3-29-2006, 2006.

Lana, A., Bell, T. G., Simó, R., Vallina, S. M., Ballabrera- Poy, J., Kettle, A. J., Dachs, J., Bopp, L., Saltzman, E. S., Stefels, J., Johnson, J. E., and Liss, P. S.: An updated climatology of surface dimethlysulfide concentrations and emission fluxes in the global ocean, Global Biogeochem. Cy., 25, GB1004, doi:10.1029/2010GB003850, 2011.

Large, W. G. and Yeager, S. G.: The global climatology of an interannually varying air-sea flux data set, Clim. Dynam., 33, 341364, 2008.

Madec, G.: NEMO ocean general circulation model reference manuel. Internal Report. LODYC/IPSL, Paris, 2008.

Mihalopoulos, N., Nguyen, B. C., Putaud, J. P., and Belviso, S.: The oceanic source of carbonyl sulfide (COS), Atmos. Environ. A-G., 26, 1383-1394, 1992. 
Montzka, S. A., Calvert, P., Hall, B. D., Elkins, J. W., Conway, T. J., Tans, P. P., and Sweeney, C.: On the global distribution, seasonality, and budget of atmospheric carbonyl sulfide (COS) and some similarities to CO2, J. Geophys. Res.-Oc. Atmos., 112, 2007.

Morel, A.: Optical modeling of the upper ocean in relation to its biogenous matter content (case I waters), J. Geophys. Res.Oceans., 93, 10749-10768, 1988.

Morel, A. and Gentili, B.: A simple band ratio technique to quantify the colored dissolved and detrital organic material from ocean color remotely sensed data, Remote Sens. Environ., 113, 9981011, 2009.

Notholt, J., Weisenstein, D., Kuang, Z., Rinsland, C. P., Toon, G. C., Rex, M., and Schrems, O.: Composition of the upper tropical troposphere and its influence on the stratospheric aerosol formation, EGS-AGU-EUG Joint Assembly (Vol. 1, p. 4024), 2003.

Para, J., Coble, P. G., Charrière, B., Tedetti, M., Fontana, C., and Sempéré, R.: Fluorescence and absorption properties of chromophoric dissolved organic matter (CDOM) in coastal surface waters of the northwestern Mediterranean Sea, influence of the Rhône River, Biogeosciences, 7, 4083-4103, doi:10.5194/bg-74083-2010, 2010.

Preiswerk, D. and Najjar, R. G.: A global, open-ocean model of carbonyl sulfide and its air-sea flux, Global Biogeochem. Cy., 14, 585-598, 2000.

Radford-Knoery, J. and Cutter, G. A.: Determination of carbonyl sulfide and hydrogen sulfide species in natural waters using specialized collection procedures and gas chromatography with flame photometric detection, Anal. Chem., 65, 976-982, 1993.

Rasmussen, R. A., Khalil, M. A. K., and Hoyt, S. D.: The oceanic source of carbonyl sulfide (OCS), Atmos. Environ., 16, 15911594, 1982.

Suntharalingam, P., Kettle, A. J., Montzka, S. M., and Jacob, D. J.: Global 3-D model analysis of the seasonal cycle of atmospheric carbonyl sulfide: Implications for terrestrial vegetation uptake, Geophys. Res. Lett., 35, L19801, doi:10.1029/2008GL034332, 2008.

Tedetti, M. and Sempéré, R.: Penetration of ultraviolet radiation in the marine environment. A review, Photochem. Photobiol., 82, 389-397, 2006.

Uher, G.: Distribution and air-sea exchange of reduced sulphur gases in European coastal waters, Estuar. Coast. Shelf. S., 70, 338-360, 2006.
Uher, G. and Andreae, M. O.: Photochemical production of carbonyl sulfide in North Sea water: A process study, Limnol. Oceanogr., 42, 432-442, 1997.

Ulshöfer, V. S., Uher, G., and Andreae, M. O.: Evidence for a winter sink of atmospheric carbonyl sulfide in the northeast Atlantic Ocean, Geophys. Res. Lett., 22, 2601-2604, 1995.

Ulshöfer, V. S., Flock, O. R., Uher, G., and Andreae, M. O.: Photochemical production and air-sea exchange of carbonyl sulfide in the eastern Mediterranean Sea, Mar. Chem., 53, 25-39, 1996.

Von Hobe, M., Cutter, G. A., Kettle, A. J., and Andreae, M. O.: Dark production: A significant source of oceanic COS, J. Geophys. Res.-Oceans., 106, 31217-31226, 2001.

Von Hobe, M., Najjar, R. G., Kettle, A. J., and Andreae, M. O.: Photochemical and physical modeling of carbonyl sulfide in the ocean, J. Geophys. Res.-Oceans., 108, 3229, doi:10.1029/2000JC000712, 2003.

Wanninkhof, R.: Relationship between wind speed and gas exchange over the ocean, J. Geophys. Res.-Oceans., 97, 73737382, 1992.

Watts, S. F.: The mass budgets of carbonyl sulfide, dimethyl sulfide, carbon disulfide and hydrogen sulfide, Atmos. Environ., 34, 761779, 2000.

Weiss, P. S., Johnson, J. E., Gammon, R. H., and Bates, T. S.: Reevaluation of the open ocean source of carbonyl sulfide to the atmosphere, J. Geophys. Res.-Oc. Atmos., 100, 23083-23092, 1995a.

Weiss, P. S., Andrews, S. S., Johnson, J. E., and Zafiriou, O. C.: Photoproduction of carbonyl sulfide in South Pacific Ocean waters as a function of irradiation wavelength, Geophys. Res. Lett., 22, 215-218, 1995b.

Wohlfahrt, G., Brilli, F., Hörtnagl, L., Xu, X., Bingemer, H., Hansel, A., and Loreto, F.: Carbonyl sulfide (COS) as a tracer for canopy photosynthesis, transpiration and stomatal conductance: potential and limitations, Plant. Cell. Environ., 35, 657-667, 2012.

Xu, X., Bingemer, H. G., Georgii, H. W., Schmidt, U., and Bartell, U.: Measurements of carbonyl sulfide (COS) in surface seawater and marine air, and estimates of the air-sea flux from observations during two Atlantic cruises, J. Geophys. Res.-Oc. Atmos., 106, 3491-3502, 2001.

Zepp, R. G. and Andreae, M. O.: Factors affecting the photochemical production of carbonyl sulfide in seawater, Geophys. Res. Lett., 21, 2813-2816, 1994. 